\title{
Fragment Size Distribution for Ice Particle Impacts on a Glass Plate
}

\author{
Mario Vargas ${ }^{1}$, Charles R. Ruggeri ${ }^{2}$ J. Michael Pereira ${ }^{3}$, and Duane M. Revilock ${ }^{4}$ \\ NASA Glenn Research Center, Cleveland, OH, 44135
}

\begin{abstract}
This work presents the results of an experimental study of ice particle impacts on a flat glass plate. The experiment was conducted at the Ballistics Impact Laboratory of NASA Glenn Research Center. The main objective of the experiment was to gain understanding about the modifications needed to the experimental configuration for a future parametric study at a larger range of values for particle diameters and other parameters. This was achieved by studying the effect of the velocity of an impacting ice particle on the post-impact fragment size and distribution for a reduced range of impacting particle diameters. Pre-impact particle diameter and velocity data were captured with a high-speed side camera. Post-impact fragment data were captured in a single frame with a 29-megapixel camera located above and normal to the target. Repeat runs were conducted for ice particles with diameters ranging from 1.7 to 2.9 millimeters, impacting at velocities between 39 and 98 meters per second. The fragment areas were measured, and the corresponding equivalent diameters and histogram distributions were calculated. Analysis of the data showed that the average equivalent diameter for the fragments in a run was an order of magnitude smaller than the diameter of the impacting ice particle. The histograms for equivalent diameter distribution were nonnormal with long tails, with most of the fragments having equivalent diameters concentrated toward the minimum value of the fragment size that could be resolved. Factors affecting the accuracy of the data during the digital imaging analysis were identified. Needed modifications to the setup to handle small size ice particles and other testing conditions were also identified.
\end{abstract}

\section{Nomenclature}

$A M E D=$ Average Mean Equivalent Diameter for one test, which is a series of runs. The average of the mean equivalent diameter for the runs of a given test

$A V \quad=$ Average velocity of the impacting ice particles, for all the runs of a given test, at a given pressure

$D \quad=$ Droplet diameter

Fragment $=$ Small particle resulting from ice particle impact

$M E D=$ Mean Equivalent Diameter, the average of the fragment equivalent diameters for a single run

Run $\quad=$ Experimental trial with one ice particle ejected at a given pressure

Test $\quad=$ A series of experimental runs at the same tank pressure and with similar ice particle diameter

\section{Introduction}

An experimental study was conducted at the Ballistics Impact Laboratory of NASA Glenn Research Center to study the impact of ice particles on a stationary glass plate target. The experiment is part of NASA efforts to study the physics involved in engine power-loss events due to ice-crystal ingestion and ice accretion formation inside engines ${ }^{1,2,3}$. Since ice accretion on internal engine parts is due to ice crystal impacts, fundamental research efforts have been directed to study the physics of ice particles impacting on a surface.

\footnotetext{
${ }^{1}$ Aerospace Engineer, Icing Branch, 21000 Brookpark Rd., AIAA Associate Fellow

${ }^{2}$ Aerospace Engineer, Ballistics Impact Laboratory, 21000 Brookpark Rd.

${ }^{3}$ Aerospace Engineer, Ballistics Impact Laboratory, 21000 Brookpark Rd.

${ }^{4}$ Aerospace Engineer, Ballistics Impact Laboratory, 21000 Brookpark Rd.
} 
In the experiment reported here, ice particles were shot from a pressure gun and impacted on a glass plate at a $45^{\circ}$ angle to the direction of motion of the impinging particle. The experimental configuration allowed to obseravation the particles before impact and the post-impact fragments. The main objective of the experiment was to gain understanding about the modifications needed to the experimental configuration for a future parametric study. This was achieved by studying the effect of the velocity of an impacting ice particle on the post-impact fragment size and distribution for a reduced range of impacting particle diameters. Pre-impact particle diameter and velocity data were captured with a high-speed side camera. Post-impact fragment data were captured in a single frame with a 29megapixel camera located above and normal to the target. The fragment areas were measured, and the corresponding equivalent diameters and histogram distributions were calculated.

For this experiment, ice crystals were modeled with spherical ice particles ranging from 1.7 to 2.9 millimeters, impacting at velocities between 39 and 98 meters per second. This range of particle sizes provides learning steps toward a more sophisticated future experimental configuration that could allow a parametric study with smaller particle diameters. Needed modifications to the setup to handle small size ice particles, and to vary temperature of the target, temperature of the ice particle, velocity of the particle and target angle were identified. Factors affecting the accuracy of the data during the digital imaging analysis were also identified, specifically thresholding methodology, spatial resolution and illumination of the target.

The experimental data helped understand the effect of velocity on the fragments size distribution. Average equivalent fragment diameter decreased with velocity, while the number of fragments increased. The histograms for equivalent diameter distribution were non-normal with long tails, with most of the fragments having equivalent diameters concentrated toward the minimum value of the fragment size that could be measured.

To double the spatial resolution the setup was modified for a limited set of runs. Two single frame cameras were used in this configuration. Each camera covered half the field of view. To accomplish this, a triangular mirror was used. The pointed part of the mirror was placed in the direction of the target, with each side of the triangle reflecting half of the field of view. One camera pointed towards one side, and the other camera pointed towards the other. To register the images recorded by the two cameras, dots were painted on the target away from the area where the ice particle was expected to impact. Illumination was also modified in this configuration. A single high intensity LED light was used with a diffuser screen. A limited number of cases were run in this new configuration and studied to determine the feasibility of using this configuration in future experiments.

The results presented here will help determine what additional improvements in the experimental configuration are needed to conduct a parametric study of impacts by ice particle of sizes comparable to ice crystals encountered by aircraft flying through ice crystal clouds.

\section{Method}

\section{A. Conceptual View of Experiment}

Figures $1 \mathrm{a}$ and $1 \mathrm{~b}$ show the conceptual view of the experimental configuration. The particle delivery system (pressure gun) ejects the ice particles towards the glass plate target. The target is set at $45^{\circ}$ with respect to the direction of motion of the particle. To observe the impact and fragmentation from a view normal to the target, a single-frame camera was placed above the target. The illumination was from below the target. A high speed digital camera was located to the side of the target. The field of view of this camera captured the particle before, during and after impact. A laser beam located at the end of the barrel and perpendicular to the particle path was used to trigger the cameras.

\section{B. Ice Particle Preparation}

The nominally spherical ice particles (Fig. 2) were prepared using the ice-compression method (Fig. 3). An ice piece was compressed between two halves of a metallic mold. Each half of the mold has a series of hemispherical hollow cavities that constitute a whole sphere when the two parts of the mold are brought together. An ice piece was compressed and crushed until the two halves of the mold touched each other. They were then separated, and spherical ice particles were removed for use in the experiment and stored in a freezer at a temperature of $20^{\circ} \mathrm{F}$.

\section{Particle Delivery System (Pressure Gun)}

To deliver the ice particles, a particle delivery system (pressure gun) was designed and fabricated at NASA's Ballistics Impact Laboratory. The pressure gun consists of a cylinder (tank), barrel, solenoid valve, breech and stopper (Fig. 4). The tank is filled and pressurized with nitrogen gas. The pressure inside the tank is monitored with a pressure gauge. The tank is connected to the barrel that guides the ice particle. In the barrel, next to the cylinder, there is a solenoid valve. When the cylinder is pressurized, and the solenoid valve is open, the gas flowing inside the barrel accelerates the ice particle that is inside the barrel at the breech. The breech is a section of the barrel located a short 
distance after the solenoid valve. At the breech, the barrel of the gun can be separated in two pieces and the ice particle can be placed inside. The particle can be placed in a sabot or on its own. Initially the particle was placed inside the barrel and ejected using a sabot but it was found that placing the particle directly in the barrel was easier and worked equally well. To avoid melting the ice particle during the time that it remains in the breech before ejection, a plastic bag filled with dry ice was placed on top of the barrel just ahead of the breech. At the end of the barrel there is a stopper (Fig.5), a short cylindrical piece. Its main function is to stop the sabot at the end of the barrel. It has the same inside diameter as the barrel but greater thickness. A perforation through the stopper allows a laser beam to cross the path of the ice particle and trigger the cameras. A large part of the data was obtained in this way.

\section{Target and Illumination}

Figure 6 shows the glass plate target and the illumination. In the initial experiments the illumination was achieved by using metal-halide discharge lamps. The lamps ran continuously without noticeable heating to the target plate. In later testing, high powered LED arrays were used in-conjunction with a high resolution machine vision camera. The LED array provided short duration light pulses that artificially created a much shorter exposure time than the camera was capable of. With this arrangement a 29-megapixel image captured at a 2 microsecond exposure was attainable.

\section{E. Imaging System to Capture Post-Impact Fragments}

To capture the post-impact fragments, an Allied Vision Prosilica GX6600 29 Megapixel camera with a $100 \mathrm{~mm}$ lens was placed above the glass plate target next to the illumination system (Fig. 7). For a given ice particle impact the camera took a single frame. This configuration gave a resolution of 48.46 pixels per millimeter $(20.6$ micrometers per pixel). The field of view and timing of the shot was chosen to maximize the fragment separation after impact allowing a more accurate measurement of the fragment size distribution. If the timing is too short, the fragments do not separate enough from each other and they cannot be isolated for measurement. If the timing is too long, many of the fragments leave the field of view affecting the measurement of the fragment size distribution and the average equivalent diameter.

\section{F. Imaging System to Measure Velocity and Diameter of Ice Particle}

The side camera, seen on the right side in Figure 6, was used to measure the velocity and diameter of the particle before impact and to capture the impact and breakup. A Photron SA-Z high speed digital camera was used at frame rates of 96000 . A wide field of view was used to capture the ice particle before and after impact. Prior to impact, the velocity was measured using commercial software capable of tracking the projectile. The software detected the projectile's silhouette and calculated position, velocity and cross-sectional area (Fig. 8). The side view did not allow to obtain post-impact fragment size distribution, but it allowed measurement of the velocity of the farthest ejected particles. The side view also provided qualitative information on the impact and breakup of the particle, and the rebound of the fragments.

\section{G. Synchronization of the Cameras with Laser Triggering}

A laser beam perpendicular to the ice particle path and located at the end of the barrel was used to detect the ice particle. The Laser module output a 5-volt TTL signal used directly by the Photron SA-Z camera. The Photron camera was set to record $10 \%$ of its memory capacity prior to sensing the particle. A time delayed TTL signal was also used to sequence the exposure of the Prosilica GX6600 camera and LED arrays. The time delay was adjustable in the order of 1 microsecond. At each test velocity, the delay had to be optimized to allow sufficient dispersion of the ice fragments without allowing any fragment to leave the field of view. The delayed signal was used by a microprocessor that controlled operation and synchronization of the Prosilica GX6600 camera and dual pulsed LED drivers (Fig. 9). The 29MP Prosilica camera has a minimum exposure of 30 microseconds therefore LED arrays were pulsed for a twomicrosecond duration at up to 16 times their rated maximum current. The LED system consisted of four 14 LED arrays and one 96 LED array for a total of 152 LEDs. The effective driving power is approximately 6000 watts.

\section{Test Procedure, Test Matrix, and Data Processing}

\section{A. Test Procedure}

Ice particles were prepared before each series of runs and the tank was set to the target pressure. The target was cleaned to remove any fragments from the previous run. The breech was opened, and one ice particle was placed inside the barrel. The time delay for the cameras was set. The breech was closed, and the gun activated. The images from the side and normal cameras to the target were examined. If the particle did not break before reaching the target 
and the images were of good quality, they were saved. The process was repeated for the next run. Before a series of runs, an image of the field of view of each camera was taken with a ruler in it to provide the length scale. This allowed calculation of the resolution in pixels per millimeter or micrometers per pixel.

\section{B. Test Matrix}

The test conditions for the runs with the camera above the glass plate are presented in Tables 1 through 9. At each pressure, which corresponds to a given velocity, 10 runs were completed.

\section{Data Processing}

A MATLAB program was developed for processing the post-impact fragments data captured with the Prosilica GX6600 camera. The program reads two images captured with the camera. One image is the background image. This image is taken with the same illumination and exposure on the target but without the impacting particle. The other image captured the post-impact fragments. The program subtracts the background image from the post-impact image, converts the resulting image from grayscale to binary (thresholding) for image segmentation, and calculates and outputs all the parameters needed for data analysis.

The side camera recorded a high-speed movie of the ice particle before and after impact. This side view allowed the measurement of the particle diameter and velocity. A post-impact side view of the particle fragments allowed observation of the behavior of the fragments with respect to the target after impact. The camera image sequence was in a proprietary raw format. The camera software was used to generate TIFF files of a movie sequence or single frame video clip and to convert from raw format to avi. The change in format from raw to AVI was done without using any compression to avoid altering the data. The camera software was also used to generate a sequence of tiff files for each run. To post-process the data from the clips, ImageJ and/or MATLAB digital imaging capabilities were used. The programs read the movies in AVI format or the TIFF files and converted each image frame from grayscale to binary for image segmentation and tracking. The ice particle (before impacting the target) was tracked to measure the diameter and velocity. The frame numbers where the tracking began and ended were selected from the video clip with help of the camera software. In each frame, the digital image processing part of the program calculates andrecords the following parameters for the particle being tracked: frame number, time with respect to the tracking frame, time with respect to the first frame of the movie, $\mathrm{x}$ coordinate of the centroid, $\mathrm{y}$ coordinate of the centroid, area, perimeter, equivalent diameter based on the measured area. The velocity is calculated from the coordinates of the centroid versus time.

\section{Results and Data Analysis}

Results and data analysis are presented here. The results from the camera above and normal to the glass plate target are given. Additionally, the effect of threshold value on the results and blurring that occurred due to fragment high velocity are presented. Factors affecting the results, modifications to the setup to improve resolution, and a conceptual view of setup for next round of experiments are discussed

\section{A. Results from Camera Above and Normal to the Glass Plate Target}

The Allied Vision Prosilica GX6600 29 Megapixel camera with $100 \mathrm{~mm}$ lens was placed above the glass plate target next to the illumination as shown in Figure 7. Only one frame was taken of the fragments after impact. The field of view was $6575 \mathrm{H}$ x $4383 \mathrm{~V}$ pixels $(150.3 \times 100.2 \mathrm{~mm})$. The resolution was 48.46 pixels per millimeter $(20.6$ micrometers per pixel). The smallest distance that could be resolved at this resolution was 20.6 micrometers.

When the pressure gun was operated, an ice particle was inserted at the breech, the tank was set at a chosen pressure, and the particle was ejected toward the target guided by the barrel. Ideally, ice particles of the same diameter will strike the target at the same velocity. In the actual running of the experiment, the diameter of the particles is not quite the same from one run to the next. Even for ice particles with similar diameters, there is some variability in the velocity of impact when ejected at the same tank pressure. Figure 10 shows this variability for ten runs conducted at a gun pressure of 9 psi. Even post-impact fragments from particles of same diameter impacting at the same velocity could be expected to show variability due to random formation of cracks during the particle fragmentation. This indicate the need to repeat the experiment at each tank pressure for ice particles with similar diameters.

Because the experiment was repeated at each tank pressure, the term "test" was used to denote a series of runs at the same tank pressure, for ice particles of similar diameter. Each test contained 10 runs. Tests were conducted for tank pressures of $3,5,7,9,11,13,15,17$, and 20 psi. At each pressure, for each run, the image of the expanding fragments was segmented, and the area of each fragment was calculated. For each fragment, the diameter of a circle with the same area was calculated and called "the equivalent diameter". For a given run, the average of the fragment 
equivalent diameters was calculated and called the "mean equivalent diameter" for that run. The "mean equivalent diameters" for all the runs at a given gun pressure were averaged and called "average mean equivalent diameter". The velocity of the impacting ice particles, for all the runs of a given test, at a given pressure, were averaged and the result called "average velocity".

Tables 1 through 9 summarize the results for tests at 3, 5 7, 9, 11, 13, 15, 17 and 20 psi. Figure 11 shows the equivalent diameter versus the run number for the 9-psi test (data in Table 4). The average mean equivalent diameter for the ten runs is 138.7 micrometers. There is some scattering of the points around the average mean equivalent diameter, and the standard deviation is 8.5. This indicates that the average mean equivalent diameter is a reasonable representation of the mean equivalent diameter from the runs. The average velocity of the impacting ice particles for the ten runs at 9 psi was $60.9 \mathrm{~m} / \mathrm{sec}$. The average diameter for the impacting ice particles was 2.5 millimeters. All the diameters of the impacting ice particles were within the range of 2.3 to 2.8 millimeters. The same calculation for tests at $3,5,7,9,11,13,15,17$ and 20 psi are presented in Table 10 .

The number of fragments were averaged for each pressure (test) and plotted against the averaged velocity for the given pressure (Fig. 12). The number of fragments increases with velocity. Intuitively this is expected since at higher velocities the kinetic energy is larger for impacting particles with the same mass. On the other hand the number of fragments for the ten runs at any pressure (test) show large scattering as can be observed in the second column of any of the Tables 1 through 9. This variability in the number of fragments is the result of several factors: (a) There is some randomness in the crack formation during impact of the particles, (b) The illumination and noise in the images for each impact are different. In this case the thresholding method of segmentation will give different values for impacts at similar velocities.

Table 10 lists the average fragments mean equivalent diameter and the average impacting particle velocity for each test. The average mean equivalent diameter shows little change with respect to the average velocity. This is counter intuitive. As the velocity of the impacting particle increases, a larger number of fragments with smaller equivalent diameters would be expected for a given run. The mean equivalent diameter for each run at higher velocities should decrease, as well as the average mean equivalent diameter for those runs. The data does not show this trend. One reason may be the resolution, which limits the minimum equivalent diameter that can be detected. The resolution used was 20.64 micrometers per pixel (48.46 pixels per millimeter). For a fragment with the minimum area of one pixel, the equivalent diameter is 1.13 pixel or 23.3 micrometers. Fragments with an equivalent diameter of 23.3 micrometers or smaller cannot be detected. The smaller fragments due to the higher impact velocities are not captured. The limitation in the resolution acts as a high-pass filter. The decrease in average fragments mean equivalent diameter resulting from impacting particles at high velocities is not captured. Another factor that influences the values of average mean equivalent diameter for large values of impacting velocities is the difficulty of the data analysis program to separate fragments that are too close to each other. At high velocities many small fragments are produced. The timing to photograph them when they are separated enough from each other, but before they leave the field of view, is too difficult to achieve. The data analysis program records one large fragment instead of individual ones in cases where the fragments are too close to each other (Fig. 13).

Figures 14 and 15 show the segmented image and histogram for Run 06 at 3 psi. In this run an ice particle with a diameter of 2.3 millimeter impacts the target at a velocity of $32 \mathrm{~m} / \mathrm{sec}$. The number of fragments is 226 . The fragments mean equivalent diameter is 149 micrometers (7.2 pixels). Small and large fragments result from the impact. The histogram (Fig. 15) shows that equivalent diameter of most of the fragments are concentrated around 30 micrometers. The histogram is non-normal and long tailed. The segmented image (Fig. 14) shows ten large fragments, all the other are smaller. The equivalent diameter of the largest fragment (shown in red) is 1742 micrometers (84.4 pixels).

Figures 16 and 17 show the segmented image and histogram for Run 06 at 20 psi. For this run, an ice particle with a diameter of 2.1 millimeter impacts the target at $99 \mathrm{~m} / \mathrm{sec}$. The number of resulting fragments is 863 . The fragments mean equivalent diameter is 133 micrometers (6.5 pixels). The histogram (Fig. 17) shows that the equivalent diameter of most of the fragments are concentrated around 30 micrometers. The histogram is non-normal and long tailed. The segmented image (Fig. 16) shows many small and medium size fragments. The equivalent diameter of the largest fragment (shown in red) is 988 micrometers (47.9 pixels).

In all the runs analyzed the fragments mean equivalent diameter for an ice particle impact is at least an order of magnitude less than the diameter of the impacting particle. All the histogram of the fragments equivalent diameter followed the same pattern: a non-normal distribution with a long tail, with most of the values concentrated near the resolution limit. This is consistent with the dynamics of ice particle impacts observed by different researchers ${ }^{4,5,6}$. The area where the particle had initial contact with the surface breaks up into very small particles ejected as a cloud of fragments at high velocity. This initial fragment cloud preceded the development of cracks and the formation of larger fragments in the remainder of the impacting ice particle. 


\section{B. Effect of Threshold Value on Results}

To measure the area of each fragment, the image with the fragments had to be changed from grayscale to binary. In a binary image the fragments appear as totally black objects against a white background. The binary image is analyzed with digital imaging techniques to identify each fragment and measure properties about them. This whole process is called segmentation. In the present work the properties measured for each fragment were: the area, the equivalent diameter, the centroid, the perimeter, and the minor and major axis of an ellipse superimposed on the fragment. When converting the image from grayscale to binary, the data analysis program uses a grayscale value above which all the pixels are converted to black color. The program calculates that value. It is called the "threshold". All the pixels with intensity value above the threshold are converted to black, the ones below are converted to white.

There is not a unique way of calculating the threshold value of an image. Several methods are available ${ }^{7}$, and they may give different values for the threshold. In the present work, when different threshold methods were used, it affected the area of the fragments and the corresponding equivalent diameters. Another factor with the different thresholding methods is determining how each one handles the noise in the image. When measuring small fragments with low levels of illumination (as is the case in this experiment), noise in pixels may create fragments that are not real. For this reason, a thresholding method was developed ${ }^{8}$ for this experiment that is more consistent and allows better control of the effect of noise in the detection and measurement of the post-impact fragments. This thresholding method was employed in segmentation of the image for all the cases presented in this report. Figure 18 shows the original image next to the segmented binary image. Comparison of the two shows that the thresholding method captured most of the details from the original image. Only very faint fragments or fragments smaller than the resolution were not captured in the binary image.

\section{Blurring due to Fragment High Velocity}

After an ice particle impacts, some of the fragments may have very high velocity. The reason is that part of the kinetic energy carried by the particle before impact is transferred to the fragments. If a small quantity of kinetic energy is transferred to a fragment it may translate into a very high velocity if the fragment has a very small mass. This high velocity may cause blurring of the fragment in the captured image and result in a higher area and equivalent diameter. To determine if there was blurring due to the motion of the fragments, the following calculation was made:

$$
\text { Maximum Exposure }=\frac{1 * 1000}{\text { resolution } * \text { Velocity of Object }}
$$

where Maximum Exposure is the maximum exposure tolerated before blurring occurs given in microseconds; resolution is the resolution in pixels per millimeter; the number " 1 " indicates the maximum number of pixels that the object is expected to move during exposure; and Velocity of the Object is the velocity of the fragment given in meters per second. For a resolution of $48.46 \mathrm{pixel} /$ millimeter and a fragment velocity of 100 meters per second, the maximum exposure allowed before blurring occurs is 0.206 microseconds. The smaller exposure used in the experiment was 1.0 microseconds therefore it should be expected that some of the smaller fragments in the analyzed images are blurred and showing larger areas and equivalent diameters than they have. It was not possible to correct for this effect in the data presented in this paper.

\section{Factors Affecting the Results}

The experiment showed that several factors affect the results. The main ones are: image noise, thresholding method, resolution limit and blurring. Another factor is the lens used with the camera above the target. The lens presents some distortion when moving from the center towards the edge of the field of view. This distortion was measured by placing spherical elements of a known diameter on the target, capturing the image and comparing the actual sizes with the ones measured from the image. It was found that the objects at the edge of the field of view presented a $10 \%$ error in size. Handling of small ice particles (less than 1000 micrometers) is very difficult at room temperature. To go to smaller particles the experiment needs to be placed in a low temperature-controlled environment. Capturing the size of fragments from impacts by ice particles with diameters less than 2000 micrometers will require improvements in the resolution. Other effects such as diffraction and shadows created by the fragments were not ignored but at this stage were deemed too difficult to quantify. 


\section{E. Modifications to the Setup to improve Resolution}

The experimental setup was modified for a limited set of runs to improve the resolution. Two Prosilica GX6600 cameras were used. Each camera pointed towards a triangular mirror (Fig. 19). Each camera covered half of the field of view, and thus the overall configuration doubled the field of view. Figure 20 shows the modified setup. Illumination was changed to a high intensity LED combined with a light diffuser. Markings on the glass target allowed registration of the images. The images needed to be rotated and combined for digital imaging analysis. A limited set of data for gun pressures of 3,5,7 and $10 \mathrm{psi}$ were obtained for proof-of-concept of the configuration. Resolutions from 5 to 10 micrometers per pixel were obtained. The results showed that the modified configuration worked but needs additional improvements. Alignment of the cameras is difficult to obtain. Illumination with a single high intensity LED creates rings of high and low intensity on the images that complicate the data processing. Registration of the images needs to be improved. With additional improvements, the modified setup could be used to test at resolution from 5-10 micrometers per pixel.

\section{F. Conceptual View of Setup for next round of Experiments}

The experiments conducted at the Ballistics Impact Laboratory indicate that the experimental setup requires major modifications to test at particle sizes and conditions that are more representative of ice crystals in aircraft engine cores. These modifications include improvements in the resolution, new approach to illumination of the target, control of target temperature, control and measurements of the ice particle temperature before impact, generation and testing of smaller ice particles at different temperatures and velocities. A new setup concept was developed (Fig. 21) with the objective of testing ice particles from 200 to 2000 micrometers in diameter at target temperatures of 100 to $400{ }^{\circ} \mathrm{F}$, ice particle temperatures of -5 to $-25^{\circ} \mathrm{F}$, velocities from 10 to $100 \mathrm{~m} / \mathrm{sec}$, and target angles from 5 to 90 degrees. To attain resolutions in the range of 5 micrometers per pixel, the lens system will be improved with the addition of a K2 lens. If needed, the two-camera system discussed in section $\mathrm{E}$ will be used. Illumination will be done with a back-lit LED BL 2D system from Advanced Illumination. The system will be operated with a strobe controller to obtain a one microsecond pulse width. Temperature of the ice particle before impacting the target will be measured using a Telops TR-IR high-speed infrared camera. The pressure gun will be placed in a low temperature, low humidity chamber. The hardware has been acquired and the new setup is being implemented with testing to follow.

\section{Conclusions}

The experimental results presented in the previous sections lead to the following conclusions:

- In all the runs analyzed, the histogram of the fragments equivalent diameter followed the same pattern: a non-normal distribution with a long tail, with most of the values concentrated near the resolution limit. This pattern was observed at all velocities.

- The limit in the resolution, 20.6 micrometers/pixel, acts as a high-pass filter not allowing the capture of most of the small fragments generated during the ice particle impacts.

- The fragments mean equivalent diameter for an ice particle impact is at least an order of magnitude less than the diameter of the impacting particle. Capturing the size of fragments from impacts by ice particles with diameters less than 2000 micrometers will require improvements in the resolution.

- Major modifications are needed to the experimental setup to test at particle sizes and conditions that are more representative of ice crystals in aircraft engine cores. These modifications include: improvements in the resolution, new approach to illumination of the target, control of the target temperature, control and measurement of the ice particle temperature before impact, generation and testing of smaller ice particles at different temperatures and velocities.

The results of the work presented here will help in the design of future experimental studies of ice crystal impacts on surfaces. The experiments are needed to understand the physics involved in the impact of ice crystals on elements in turbofan engines which is one of the current main areas of engine icing studies. 


\section{Acknowledgments}

The authors would like to thank Mr. Jeff Hammel, Lead Mechanic at the Ballistics Impact Laboratory of NASA Glenn Research Center. The research work is funded by the Advanced Air Transport Technology (AATT) Project.

\section{References}

${ }^{1}$ Mason, J. G., Strapp, J.W., and Chow, P., "The Ice Particle Threat to Engines in Flight," AIAA 2006-206, 44th AIAA Aerospace Sciences Meeting and Exhibit, Reno NV, January 2006

2Electronic Code of Federal Regulations, Title 14, Part 33, "Airworthiness Standards: Aircraft Engines," [Online], http://www.ecfr.gov/cgi-bin/text-idx?c=ecfr\&tpl=/ecfrbrowse/Title14/14tab_02.tpl [Cited March 12, 2014].

${ }^{3}$ Federal Register Proposed Rules, Airplane and Engine Certification Requirements: "Supercooled Large Drop, Mixed Phase, and Ice Crystal Icing Conditions," FR DOC \#: 2010-15726, Vol. 75, No. 124, pp. 37311-37339, June 29, 2010.

${ }^{4}$ Guégan, P., Othman, R., Lebreton, D., Pasco, F., Villedieu, P., Meyssonnier, J., and Wintenberger, S., "Experimental Investigation of the Kinematics of Post-impact Ice Fragments," International Journal of Impact Engineering, Vol. 38, No. 10, 2011, pp. 786-795.

${ }^{5}$ Guégan, P., Othman, R., Lebreton, D., Pasco, F., Villedieu, P., Meyssonnier, J., and Wintenberger, S., "Critical impact velocity for ice fragmentation," Proc IMechE Part C, J Mechanical Engineering Science, Vol. 226, No. 7, 2011, pp. 1677-1682.

${ }^{6}$ Vargas, M., Ruggeri, C., Struk, P., Pereira, M., Revilock, D., Kreeger, R.: "Ice Particle Impacts on a Flat Plate," 2015-012099, SAE 2015 International Conference on Icing of Aircraft, Engines, and Structures, Prague, June 2015

${ }^{7}$ Otsu, N., "A Threshold Selection Method from Gray-Level Histograms," IEEE Transactions on Systems, Man, and Cybernetics, Vol. 9, No. 1, 1979, pp. 62-66.

${ }^{8}$ Vargas, M., Ruggeri, C., Pereira, M., Revilock, D.: "Signal-to-Noise Ratio Thresholding Method," to be published 
Table 1. 3 psi Data

\begin{tabular}{|c|c|c|c|c|c|c|c|c|c|c|c|c|}
\hline Run Number & $\begin{array}{l}\text { Number of } \\
\text { Fragments }\end{array}$ & $\begin{array}{c}\text { Maximum } \\
\text { Fragment } \\
\text { Area }\end{array}$ & $\begin{array}{l}\text { Fragments } \\
\text { Mean Area }\end{array}$ & $\begin{array}{c}\text { Fragments } \\
\text { Median Area }\end{array}$ & $\begin{array}{l}\text { Fragments } \\
\text { Minimum } \\
\text { Equivalent } \\
\text { Diameter }\end{array}$ & $\begin{array}{c}\text { Fragments } \\
\text { Maximum } \\
\text { Equivalent } \\
\text { Diameter }\end{array}$ & $\begin{array}{l}\text { Fragments } \\
\text { Mean } \\
\text { Equivalent } \\
\text { Diameter }\end{array}$ & $\begin{array}{l}\text { Fragments } \\
\text { Median } \\
\text { Equivalent } \\
\text { Diameter }\end{array}$ & Resolution & Target Angle & $\begin{array}{l}\text { Ice Particle } \\
\text { Diameter }\end{array}$ & $\begin{array}{l}\text { Particle } \\
\text { Velocity }\end{array}$ \\
\hline & & (pixels) & (pixels) & (pixels) & (pixels) & (pixels) & (pixels) & (pixels) & (pixels/mm) & (degrees) & $(\mathrm{mm})$ & $(\mathrm{m} / \mathrm{sec})$ \\
\hline 01 & 212 & 6572 & 133.17 & 14.5 & 1.13 & 91.48 & 7.61 & 4.30 & 48.46 & 45 & 2.22 & 30.57 \\
\hline 02 & 231 & 7713 & 192.21 & 18 & 1.13 & 99.10 & 8.48 & 4.79 & 48.46 & 45 & 2.36 & 29.22 \\
\hline 03 & 142 & 8538 & 166.84 & 8 & 1.13 & 104.26 & 6.91 & 3.19 & 48.46 & 45 & 2.56 & 31.35 \\
\hline 04 & 317 & 3833 & 119.87 & 20 & 1.13 & 69.86 & 7.54 & 5.05 & 48.46 & 45 & 2.29 & 30.41 \\
\hline 05 & 288 & 6937 & 151.68 & 13 & 1.13 & 93.98 & 7.89 & 4.07 & 48.46 & 45 & 2.64 & 29.58 \\
\hline 06 & 226 & 5589 & 134.12 & 11 & 1.13 & 84.36 & 7.23 & 3.74 & 48.46 & 45 & 2.28 & 31.92 \\
\hline 07 & 409 & 6980 & 111.68 & 19 & 1.13 & 94.27 & 7.45 & 4.92 & 48.46 & 45 & 2.47 & 31.14 \\
\hline 08 & 256 & 2879 & 66.06 & 6 & 1.13 & 60.54 & 5.11 & 2.76 & 48.46 & 45 & 2.17 & 34.96 \\
\hline 09 & 257 & 12384 & 132.82 & 10 & 1.13 & 125.57 & 6.34 & 3.57 & 48.46 & 45 & 2.51 & 29.54 \\
\hline 10 & 351 & 7855 & 93.73 & 10 & 1.13 & 100.01 & 6.21 & 3.57 & 48.46 & 45 & 2.51 & 32.52 \\
\hline
\end{tabular}

Table 2. 5 psi Data

\begin{tabular}{|c|c|c|c|c|c|c|c|c|c|c|c|c|}
\hline Run Number & $\begin{array}{l}\text { Number of } \\
\text { Fragments }\end{array}$ & $\begin{array}{c}\text { Maximum } \\
\text { Fragment } \\
\text { Area }\end{array}$ & $\begin{array}{l}\text { Fragments } \\
\text { Mean Area }\end{array}$ & $\begin{array}{c}\text { Fragments } \\
\text { Median Area }\end{array}$ & $\begin{array}{c}\text { Fragments } \\
\text { Minimum } \\
\text { Equivalent } \\
\text { Diameter }\end{array}$ & $\begin{array}{c}\text { Fragments } \\
\text { Maximum } \\
\text { Equivalent } \\
\text { Diameter }\end{array}$ & $\begin{array}{l}\text { Fragments } \\
\text { Mean } \\
\text { Equivalent } \\
\text { Diameter }\end{array}$ & $\begin{array}{c}\text { Fragments } \\
\text { Median } \\
\text { Equivalent } \\
\text { Diameter }\end{array}$ & Resolution & Target Angle & $\begin{array}{l}\text { Ice Particle } \\
\text { Diameter }\end{array}$ & $\begin{array}{l}\text { Particle } \\
\text { Velocity }\end{array}$ \\
\hline & & (pixels) & (pixels) & (pixels) & (pixels) & (pixels) & (pixels) & (pixels) & (pixels/mm) & (degrees) & $(\mathrm{mm})$ & $(\mathrm{m} / \mathrm{sec})$ \\
\hline 01 & 284 & 5686 & 78.58 & 9 & 1.13 & 85.09 & 5.83 & 3.39 & 48.46 & 45 & 2.21 & 39.42 \\
\hline 02 & 541 & 2887 & 83.38 & 11 & 1.13 & 60.63 & 6.22 & 3.74 & 48.46 & 45 & 2.46 & 40.43 \\
\hline 03 & 324 & 5073 & 67.25 & 6 & 1.13 & 80.37 & 4.97 & 2.76 & 48.46 & 45 & 2.20 & 43.84 \\
\hline 04 & 370 & 5816 & 84.45 & 7 & 1.13 & 86.05 & 5.90 & 2.99 & 48.46 & 45 & 2.36 & 40.77 \\
\hline 05 & 501 & 5700 & 86.84 & 9 & 1.13 & 85.19 & 5.93 & 3.39 & 48.46 & 45 & 2.48 & 40.37 \\
\hline 06 & 359 & 3465 & 97.32 & 8 & 1.13 & 66.42 & 6.19 & 3.19 & 48.46 & 45 & 2.55 & 41.98 \\
\hline 07 & 276 & 3269 & 99.87 & 8 & 1.13 & 64.52 & 6.36 & 3.19 & 48.46 & 45 & 2.07 & 39.35 \\
\hline 08 & 215 & 6671 & 67.63 & 8 & 1.13 & 92.16 & 5.08 & 3.19 & 48.46 & 45 & 2.12 & 41.09 \\
\hline 09 & 380 & 5980 & 71.66 & 6 & 1.13 & 87.26 & 5.39 & 2.76 & 48.46 & 45 & 2.31 & 40.82 \\
\hline 10 & 368 & 3484 & 74.73 & 9 & 1.13 & 66.60 & 5.56 & 3.39 & 48.46 & 45 & 2.23 & 43.24 \\
\hline
\end{tabular}

Table 3. 7 psi Data

\begin{tabular}{|c|c|c|c|c|c|c|c|c|c|c|c|c|}
\hline Run Number & $\begin{array}{l}\text { Number of } \\
\text { Fragments }\end{array}$ & $\begin{array}{c}\text { Maximum } \\
\text { Fragment } \\
\text { Area }\end{array}$ & $\begin{array}{l}\text { Fragments } \\
\text { Mean Area }\end{array}$ & $\begin{array}{c}\text { Fragments } \\
\text { Median Area }\end{array}$ & $\begin{array}{c}\text { Fragments } \\
\text { Minimum } \\
\text { Equivalent } \\
\text { Diameter }\end{array}$ & $\begin{array}{c}\text { Fragments } \\
\text { Maximum } \\
\text { Equivalent } \\
\text { Diameter }\end{array}$ & $\begin{array}{l}\text { Fragments } \\
\text { Mean } \\
\text { Equivalent } \\
\text { Diameter }\end{array}$ & $\begin{array}{l}\text { Fragments } \\
\text { Median } \\
\text { Equivalent } \\
\text { Diameter }\end{array}$ & Resolution & Target Angle & $\begin{array}{c}\text { Ice Particle } \\
\text { Diameter }\end{array}$ & $\begin{array}{l}\text { Particle } \\
\text { Velocity }\end{array}$ \\
\hline & & (pixels) & (pixels) & (pixels) & (pixels) & (pixels) & (pixels) & (pixels) & (pixels/mm) & (degrees) & $(\mathrm{mm})$ & $(\mathrm{m} / \mathrm{sec})$ \\
\hline 01 & 413 & 4856 & 90.76 & 12 & 1.13 & 78.63 & 6.85 & 3.91 & 48.46 & 45 & 2.21 & 39.42 \\
\hline 02 & 399 & 4406 & 106.43 & 19 & 1.13 & 74.90 & 7.44 & 4.92 & 48.46 & 45 & 2.22 & 48.82 \\
\hline 03 & 419 & 3292 & 62.12 & 6 & 1.13 & 64.74 & 5.23 & 2.76 & 48.46 & 45 & 2.19 & 52.55 \\
\hline 04 & 594 & 4990 & 80.06 & 13 & 1.13 & 79.71 & 6.38 & 4.07 & 48.46 & 45 & 2.51 & 53.21 \\
\hline 05 & 655 & 2921 & 84.47 & 16 & 1.13 & 60.98 & 6.73 & 4.51 & 48.46 & 45 & 2.36 & 49.12 \\
\hline 06 & 240 & 5326 & 63.18 & 7 & 1.13 & 82.35 & 5.03 & 2.99 & 48.46 & 45 & 1.72 & 48.94 \\
\hline 07 & 733 & 5724 & 80.58 & 12 & 1.13 & 85.37 & 6.19 & 3.91 & 48.46 & 45 & 2.62 & 51.37 \\
\hline 08 & 513 & 5044 & 72.48 & 8 & 1.13 & 80.14 & 5.67 & 3.19 & 48.46 & 45 & 2.39 & 51.81 \\
\hline 09 & 515 & 4321 & 73.74 & 11 & 1.13 & 74.17 & 5.97 & 3.74 & 48.46 & 45 & 2.27 & 51.39 \\
\hline 10 & 416 & 9768 & 76.19 & 9 & 1.13 & 111.52 & 5.47 & 3.39 & 48.46 & 45 & 2.47 & 55.49 \\
\hline
\end{tabular}


Table 4. 9 psi Data

\begin{tabular}{|c|c|c|c|c|c|c|c|c|c|c|c|c|}
\hline Run Number & $\begin{array}{l}\text { Number of } \\
\text { Fragments }\end{array}$ & $\begin{array}{l}\text { Maximum } \\
\text { Fragment } \\
\text { Area }\end{array}$ & $\begin{array}{l}\text { Fragments } \\
\text { Mean Area }\end{array}$ & $\begin{array}{c}\text { Fragments } \\
\text { Median Area }\end{array}$ & $\begin{array}{l}\text { Fragments } \\
\text { Minimum } \\
\text { Equivalent } \\
\text { Diameter }\end{array}$ & $\begin{array}{l}\text { Fragments } \\
\text { Maximum } \\
\text { Equivalent } \\
\text { Diameter }\end{array}$ & $\begin{array}{l}\text { Fragments } \\
\text { Mean } \\
\text { Equivalent } \\
\text { Diameter }\end{array}$ & $\begin{array}{l}\text { Fragments } \\
\text { Median } \\
\text { Equivalent } \\
\text { Diameter }\end{array}$ & Resolution & Target Angle & $\begin{array}{l}\text { Ice Particle } \\
\text { Diameter }\end{array}$ & $\begin{array}{l}\text { Particle } \\
\text { Velocity }\end{array}$ \\
\hline & & (pixels) & (pixels) & (pixels) & (pixels) & (pixels) & (pixels) & (pixels) & (pixels/mm) & (degrees) & $(\mathrm{mm})$ & (m/sec) \\
\hline 01 & 773 & 4029 & 86.12 & 17 & 1.13 & 71.62 & 6.76 & 4.65 & 48.46 & 45 & 2.57 & 62.84 \\
\hline 02 & 754 & 3143 & 88.74 & 15 & 1.13 & 63.26 & 6.90 & 4.37 & 48.46 & 45 & 2.44 & 60.65 \\
\hline 03 & 937 & 9915 & 113.44 & 15 & 1.13 & 112.36 & 7.30 & 4.37 & 48.46 & 45 & 2.58 & 59.05 \\
\hline 04 & 330 & 7614 & 90.83 & 13 & 1.13 & 98.46 & 6.10 & 4.07 & 48.46 & 45 & 2.38 & 59.43 \\
\hline 05 & 1012 & 4956 & 95.94 & 15.5 & 1.13 & 79.44 & 7.01 & 4.44 & 48.46 & 45 & 2.53 & 58.52 \\
\hline 06 & 1167 & 4124 & 78.27 & 14 & 1.13 & 72.46 & 6.41 & 4.22 & 48.46 & 45 & 2.76 & 63.11 \\
\hline 07 & 867 & 6072 & 84.92 & 13 & 1.13 & 87.93 & 6.53 & 4.07 & 48.46 & 45 & 2.51 & 60.40 \\
\hline 08 & 452 & 3590 & 69.55 & 14 & 1.13 & 67.61 & 6.12 & 4.22 & 48.46 & 45 & 2.41 & 65.37 \\
\hline 09 & 1214 & 4108 & 96.98 & 16 & 1.13 & 72.32 & 7.03 & 4.51 & 48.46 & 45 & 2.70 & 60.67 \\
\hline 10 & 588 & 3412 & 94.73 & 15.5 & 1.13 & 65.91 & 7.05 & 4.44 & 48.46 & 45 & 2.31 & 59.00 \\
\hline
\end{tabular}

Table 5. 11 psi Data

\begin{tabular}{|c|c|c|c|c|c|c|c|c|c|c|c|c|}
\hline Run Number & $\begin{array}{l}\text { Number of } \\
\text { Fragments }\end{array}$ & $\begin{array}{c}\text { Maximum } \\
\text { Fragment } \\
\text { Area }\end{array}$ & $\begin{array}{l}\text { Fragments } \\
\text { Mean Area }\end{array}$ & $\begin{array}{c}\text { Fragments } \\
\text { Median Area }\end{array}$ & $\begin{array}{l}\text { Fragments } \\
\text { Minimum } \\
\text { Equivalent } \\
\text { Diameter }\end{array}$ & $\begin{array}{l}\text { Fragments } \\
\text { Maximum } \\
\text { Equivalent } \\
\text { Diameter }\end{array}$ & $\begin{array}{l}\text { Fragments } \\
\text { Mean } \\
\text { Equivalent } \\
\text { Diameter }\end{array}$ & $\begin{array}{l}\text { Fragments } \\
\text { Median } \\
\text { Equivalent } \\
\text { Diameter }\end{array}$ & Resolution & Target Angle & $\begin{array}{l}\text { Ice Particle } \\
\text { Diameter }\end{array}$ & $\begin{array}{l}\text { Particle } \\
\text { Velocity }\end{array}$ \\
\hline & & (pixels) & (pixels) & (pixels) & (pixels) & (pixels) & (pixels) & (pixels) & (pixels/mm) & (degrees) & $(\mathrm{mm})$ & $(\mathrm{m} / \mathrm{sec})$ \\
\hline 01 & 977 & 2635 & 85.60 & 15 & 1.13 & 57.92 & 6.75 & 4.37 & 48.46 & 45 & 2.58 & 66.64 \\
\hline 02 & 1171 & 2510 & 75.71 & 17 & 1.13 & 56.53 & 6.73 & 4.65 & 48.46 & 45 & 2.44 & 67.25 \\
\hline 03 & 969 & 5222 & 90.06 & 17 & 1.13 & 81.54 & 6.93 & 4.65 & 48.46 & 45 & 2.46 & 63.83 \\
\hline 04 & 1304 & 2941 & 78.41 & 16 & 1.13 & 61.19 & 6.68 & 4.51 & 48.46 & 45 & 2.73 & 67.58 \\
\hline 05 & 649 & 3964 & 67.62 & 15 & 1.13 & 71.04 & 6.36 & 4.37 & 48.46 & 45 & 2.28 & 67.79 \\
\hline 06 & 1065 & 2381 & 78.27 & 15 & 1.13 & 55.06 & 6.64 & 4.37 & 48.46 & 45 & 2.46 & 67.66 \\
\hline 07 & 626 & 2613 & 86.08 & 17 & 1.13 & 57.68 & 7.16 & 4.65 & 48.46 & 45 & 2.25 & 67.60 \\
\hline 08 & 915 & 2704 & 104.29 & 20 & 1.13 & 58.68 & 7.79 & 5.05 & 48.46 & 45 & 2.34 & 66.57 \\
\hline 09 & 1027 & 8275 & 106.96 & 14 & 1.13 & 102.65 & 7.19 & 4.22 & 48.46 & 45 & 2.51 & 65.63 \\
\hline 10 & 735 & 7563 & 102.53 & 17 & 1.13 & 98.13 & 7.11 & 4.65 & 48.46 & 45 & 2.76 & 68.46 \\
\hline
\end{tabular}

Table 6. 13 psi Data

\begin{tabular}{|c|c|c|c|c|c|c|c|c|c|c|c|c|}
\hline Run Number & $\begin{array}{l}\text { Number of } \\
\text { Fragments }\end{array}$ & $\begin{array}{c}\text { Maximum } \\
\text { Fragment } \\
\text { Area }\end{array}$ & $\begin{array}{l}\text { Fragments } \\
\text { Mean Area }\end{array}$ & $\begin{array}{c}\text { Fragments } \\
\text { Median Area }\end{array}$ & $\begin{array}{l}\text { Fragments } \\
\text { Minimum } \\
\text { Equivalent } \\
\text { Diameter }\end{array}$ & $\begin{array}{c}\text { Fragments } \\
\text { Maximum } \\
\text { Equivalent } \\
\text { Diameter }\end{array}$ & $\begin{array}{l}\text { Fragments } \\
\text { Mean } \\
\text { Equivalent } \\
\text { Diameter }\end{array}$ & $\begin{array}{l}\text { Fragments } \\
\text { Median } \\
\text { Equivalent } \\
\text { Diameter }\end{array}$ & Resolution & Target Angle & $\begin{array}{l}\text { Ice Particle } \\
\text { Diameter }\end{array}$ & $\begin{array}{l}\text { Particle } \\
\text { Velocity }\end{array}$ \\
\hline & & (pixels) & (pixels) & (pixels) & (pixels) & (pixels) & (pixels) & (pixels) & (pixels/mm) & (degrees) & $(\mathrm{mm})$ & $(\mathrm{m} / \mathrm{sec})$ \\
\hline 01 & 1086 & 3254 & 78.68 & 18.5 & 1.13 & 64.37 & 6.78 & 4.85 & 48.46 & 45 & 2.52 & 74.87 \\
\hline 02 & 485 & 2772 & 52.32 & 13 & 1.13 & 59.41 & 5.47 & 4.07 & 48.46 & 45 & 2.19 & 88.35 \\
\hline 03 & 610 & 2353 & 74.55 & 18 & 1.13 & 54.74 & 6.68 & 4.79 & 48.46 & 45 & 2.37 & 77.30 \\
\hline 04 & 810 & 5999 & 73.68 & 16 & 1.13 & 87.40 & 6.38 & 4.51 & 48.46 & 45 & 2.38 & 76.07 \\
\hline 05 & 641 & 3545 & 74.17 & 17 & 1.13 & 67.18 & 6.50 & 4.65 & 48.46 & 45 & 2.27 & 75.09 \\
\hline 06 & 822 & 4872 & 84.64 & 14.5 & 1.13 & 78.76 & 6.70 & 4.30 & 48.46 & 45 & 2.40 & 72.06 \\
\hline 07 & 689 & 2673 & 81.81 & 18 & 1.13 & 58.34 & 7.01 & 4.79 & 48.46 & 45 & 2.08 & 75.41 \\
\hline 08 & 826 & 4440 & 97.07 & 18 & 1.13 & 75.19 & 7.41 & 4.79 & 48.46 & 45 & 2.50 & 73.80 \\
\hline 09 & 562 & 6157 & 117.22 & 15.5 & 1.13 & 88.54 & 7.31 & 4.44 & 48.46 & 45 & 2.40 & 71.74 \\
\hline 10 & 1076 & 4142 & 71.43 & 18 & 1.13 & 72.62 & 6.68 & 4.79 & 48.46 & 45 & 2.16 & 75.69 \\
\hline
\end{tabular}


Table 7. 15 psi Data

\begin{tabular}{|c|c|c|c|c|c|c|c|c|c|c|c|c|}
\hline Run Number & $\begin{array}{l}\text { Number of } \\
\text { Fragments }\end{array}$ & $\begin{array}{c}\text { Maximum } \\
\text { Fragment } \\
\text { Area }\end{array}$ & $\begin{array}{l}\text { Fragments } \\
\text { Mean Area }\end{array}$ & $\begin{array}{c}\text { Fragments } \\
\text { Median Area }\end{array}$ & $\begin{array}{l}\text { Fragments } \\
\text { Minimum } \\
\text { Equivalent } \\
\text { Diameter }\end{array}$ & $\begin{array}{l}\text { Fragments } \\
\text { Maximum } \\
\text { Equivalent } \\
\text { Diameter }\end{array}$ & $\begin{array}{l}\text { Fragments } \\
\text { Mean } \\
\text { Equivalent } \\
\text { Diameter }\end{array}$ & $\begin{array}{l}\text { Fragments } \\
\text { Median } \\
\text { Equivalent } \\
\text { Diameter }\end{array}$ & Resolution & Target Angle & $\begin{array}{l}\text { Ice Particle } \\
\text { Diameter }\end{array}$ & $\begin{array}{l}\text { Particle } \\
\text { Velocity }\end{array}$ \\
\hline & & (pixels) & (pixels) & (pixels) & (pixels) & (pixels) & (pixels) & (pixels) & (pixels/mm) & (degrees) & $(\mathrm{mm})$ & $(\mathrm{m} / \mathrm{sec})$ \\
\hline 01 & 391 & 2664 & 89.54 & 17 & 1.13 & 58.24 & 6.98 & 4.65 & 48.46 & 45 & 2.05 & 74.03 \\
\hline 02 & 869 & 2138 & 76.64 & 20 & 1.13 & 52.17 & 7.02 & 5.05 & 48.46 & 45 & 2.19 & 80.37 \\
\hline 03 & 650 & 2344 & 58.12 & 13 & 1.13 & 54.63 & 5.90 & 4.07 & 48.46 & 45 & 2.05 & 82.99 \\
\hline 04 & 846 & 2057 & 70.25 & 17 & 1.13 & 51.18 & 6.57 & 4.65 & 48.46 & 45 & 2.21 & 84.02 \\
\hline 05 & 975 & 6200 & 81.06 & 17 & 1.13 & 88.85 & 6.80 & 4.65 & 48.46 & 45 & 2.67 & 82.92 \\
\hline 06 & 841 & 2513 & 58.45 & 13 & 1.13 & 56.57 & 6.00 & 4.07 & 48.46 & 45 & 2.14 & 84.17 \\
\hline 07 & 813 & 5518 & 95.10 & 17 & 1.13 & 83.82 & 7.19 & 4.65 & 48.46 & 45 & 2.32 & 75.36 \\
\hline 08 & 350 & 1441 & 64.35 & 15 & 1.13 & 42.83 & 6.26 & 4.37 & 48.46 & 45 & 1.79 & 82.80 \\
\hline 09 & 1027 & 1988 & 54.85 & 16 & 1.13 & 50.31 & 6.08 & 4.51 & 48.46 & 45 & 2.53 & 90.20 \\
\hline 10 & 1046 & 23496 & 106.90 & 9 & 1.13 & 172.96 & 6.29 & 3.39 & 48.46 & 45 & 2.71 & 77.27 \\
\hline
\end{tabular}

Table 8. 17 psi Data

\begin{tabular}{|c|c|c|c|c|c|c|c|c|c|c|c|c|}
\hline Run Number & $\begin{array}{l}\text { Number of } \\
\text { Fragments }\end{array}$ & $\begin{array}{c}\text { Maximum } \\
\text { Fragment } \\
\text { Area }\end{array}$ & $\begin{array}{l}\text { Fragments } \\
\text { Mean Area }\end{array}$ & $\begin{array}{c}\text { Fragments } \\
\text { Median Area }\end{array}$ & $\begin{array}{l}\text { Fragments } \\
\text { Minimum } \\
\text { Equivalent } \\
\text { Diameter }\end{array}$ & $\begin{array}{l}\text { Fragments } \\
\text { Maximum } \\
\text { Equivalent } \\
\text { Diameter }\end{array}$ & $\begin{array}{l}\text { Fragments } \\
\text { Mean } \\
\text { Equivalent } \\
\text { Diameter }\end{array}$ & $\begin{array}{l}\text { Fragments } \\
\text { Median } \\
\text { Equivalent } \\
\text { Diameter }\end{array}$ & Resolution & Target Angle & $\begin{array}{l}\text { Ice Particle } \\
\text { Diameter }\end{array}$ & $\begin{array}{l}\text { Particle } \\
\text { Velocity }\end{array}$ \\
\hline & & (pixels) & (pixels) & (pixels) & (pixels) & (pixels) & (pixels) & (pixels) & (pixels/mm) & (degrees) & $(\mathrm{mm})$ & $(\mathrm{m} / \mathrm{sec})$ \\
\hline 01 & 1728 & 18991 & 83.29 & 12 & 1.13 & 155.50 & 6.44 & 3.91 & 48.46 & 45 & 2.61 & 88.29 \\
\hline 02 & 1738 & 3402 & 82.04 & 12 & 1.13 & 65.81 & 6.34 & 3.91 & 48.46 & 45 & 2.79 & 85.93 \\
\hline 03 & 1581 & 7539 & 71.77 & 15 & 1.13 & 97.97 & 6.51 & 4.37 & 48.46 & 45 & 2.63 & 86.61 \\
\hline 04 & 1633 & 17616 & 88.78 & 13 & 1.13 & 149.76 & 6.50 & 4.07 & 48.46 & 45 & 2.47 & 87.95 \\
\hline 05 & 1364 & 6463 & 79.81 & 18 & 1.13 & 90.71 & 6.89 & 4.79 & 48.46 & 45 & 2.20 & 83.95 \\
\hline 06 & 1164 & 6387 & 83.50 & 17 & 1.13 & 90.18 & 7.02 & 4.65 & 48.46 & 45 & 2.37 & 84.33 \\
\hline 07 & 1425 & 44756 & 126.19 & 11 & 1.13 & 238.72 & 6.71 & 3.74 & 48.46 & 45 & 2.89 & 83.66 \\
\hline 08 & 1296 & 45256 & 121.66 & 15 & 1.13 & 240.05 & 6.95 & 4.37 & 48.46 & 45 & 2.66 & 82.90 \\
\hline 09 & 1237 & 28992 & 113.65 & 7 & 1.13 & 192.13 & 6.49 & 2.99 & 48.46 & 45 & 2.77 & 77.87 \\
\hline 10 & 744 & 4384 & 87.48 & 11.5 & 1.13 & 74.71 & 6.57 & 3.83 & 48.46 & 45 & 2.69 & 84.15 \\
\hline
\end{tabular}

Table 9. 20 psi Data

\begin{tabular}{|c|c|c|c|c|c|c|c|c|c|c|c|c|}
\hline Run Number & $\begin{array}{l}\text { Number of } \\
\text { Fragments }\end{array}$ & $\begin{array}{c}\text { Maximum } \\
\text { Fragment } \\
\text { Area }\end{array}$ & $\begin{array}{l}\text { Fragments } \\
\text { Mean Area }\end{array}$ & $\begin{array}{c}\text { Fragments } \\
\text { Median Area }\end{array}$ & $\begin{array}{l}\text { Fragments } \\
\text { Minimum } \\
\text { Equivalent } \\
\text { Diameter }\end{array}$ & $\begin{array}{c}\text { Fragments } \\
\text { Maximum } \\
\text { Equivalent } \\
\text { Diameter }\end{array}$ & $\begin{array}{l}\text { Fragments } \\
\text { Mean } \\
\text { Equivalent } \\
\text { Diameter }\end{array}$ & $\begin{array}{l}\text { Fragments } \\
\text { Median } \\
\text { Equivalent } \\
\text { Diameter }\end{array}$ & Resolution & Target Angle & $\begin{array}{l}\text { Ice Particle } \\
\text { Diameter }\end{array}$ & $\begin{array}{l}\text { Particle } \\
\text { Velocity }\end{array}$ \\
\hline & & (pixels) & (pixels) & (pixels) & (pixels) & (pixels) & (pixels) & (pixels) & (pixels/mm) & (degrees) & $(\mathrm{mm})$ & (m/sec) \\
\hline 01 & 1360 & 10275 & 63.90 & 13 & 1.13 & 114.38 & 5.90 & 4.07 & 48.46 & 45 & 2.47 & 91.43 \\
\hline 02 & 2127 & 13565 & 90.81 & 13 & 1.13 & 131.42 & 6.67 & 4.07 & 48.46 & 45 & 2.73 & 87.65 \\
\hline 03 & 785 & 1808 & 48.17 & 16 & 1.13 & 47.98 & 5.62 & 4.51 & 48.46 & 45 & 2.29 & 97.08 \\
\hline 04 & 1217 & 4037 & 69.67 & 13 & 1.13 & 71.69 & 6.25 & 4.07 & 48.46 & 45 & 2.63 & 95.42 \\
\hline 05 & 1799 & 10698 & 85.81 & 13 & 1.13 & 116.71 & 6.47 & 4.07 & 48.46 & 45 & 2.77 & 93.16 \\
\hline 06 & 863 & 1802 & 65.83 & 15 & 1.13 & 47.90 & 6.45 & 4.37 & 48.46 & 45 & 2.09 & 98.73 \\
\hline 07 & 1772 & 10270 & 103.08 & 9 & 1.13 & 114.35 & 6.56 & 3.39 & 48.46 & 45 & 2.69 & 91.06 \\
\hline 08 & 1617 & 34614 & 113.76 & 13 & 1.13 & 209.93 & 6.82 & 4.07 & 48.46 & 45 & 2.43 & 88.56 \\
\hline 09 & 1450 & 8078 & 115.04 & 12 & 1.13 & 101.42 & 7.10 & 3.91 & 48.46 & 45 & 2.63 & 91.94 \\
\hline 10 & 1430 & 38222 & 108.66 & 8 & 1.13 & 220.60 & 6.33 & 3.19 & 48.46 & 45 & 2.49 & 91.20 \\
\hline
\end{tabular}


Table 10. Average Results for Tests at 3, 5, 7, 9, 11, 13, 15, 17 and 20 psi

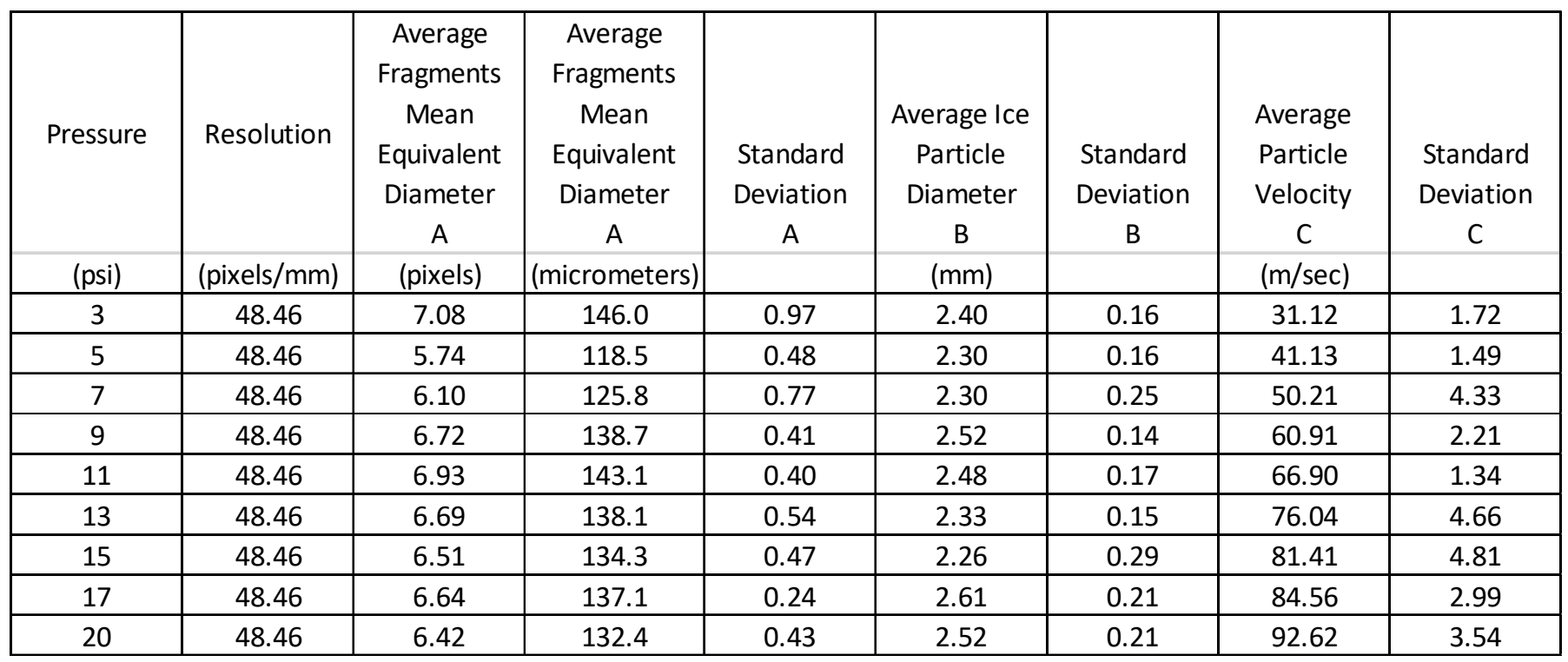




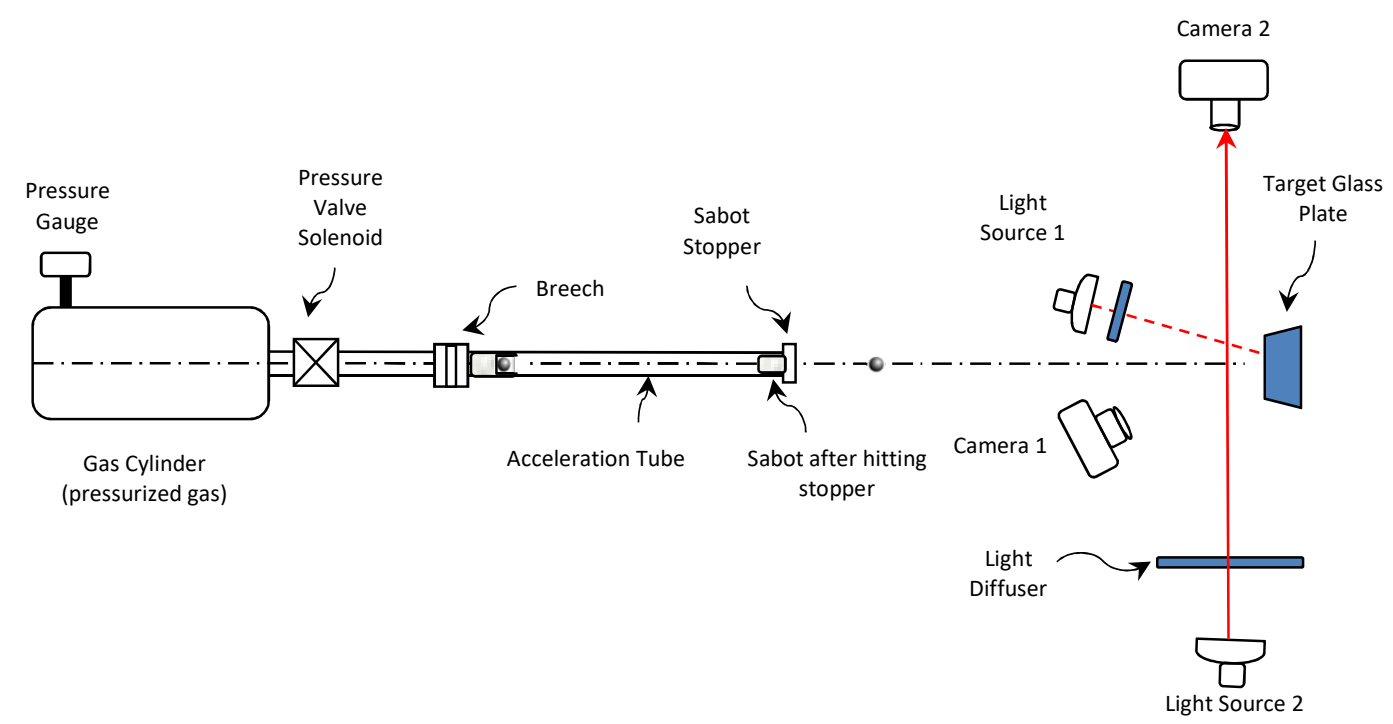

Figure 1a. Conceptual View of the Experiment - View from above

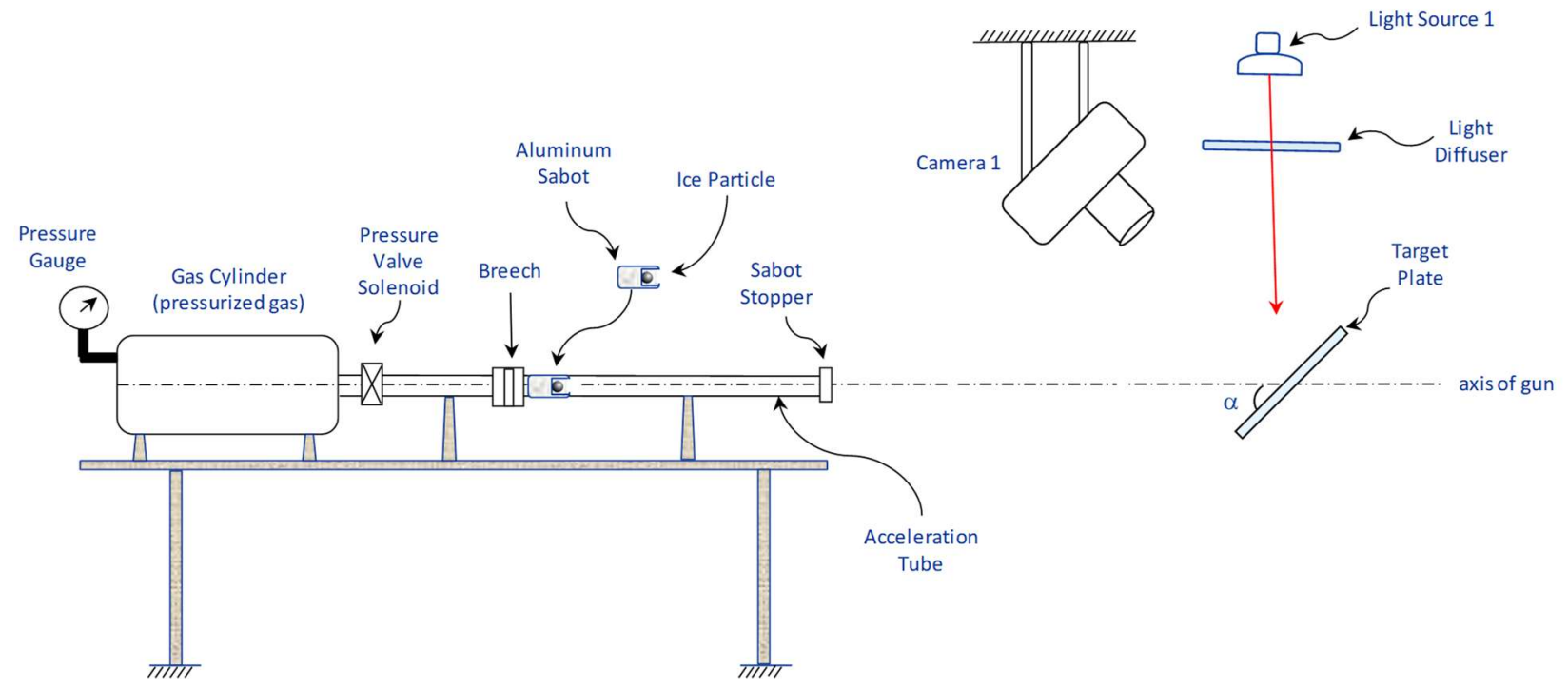

Figure 1b. Conceptual View of the Experiment - View from the side 


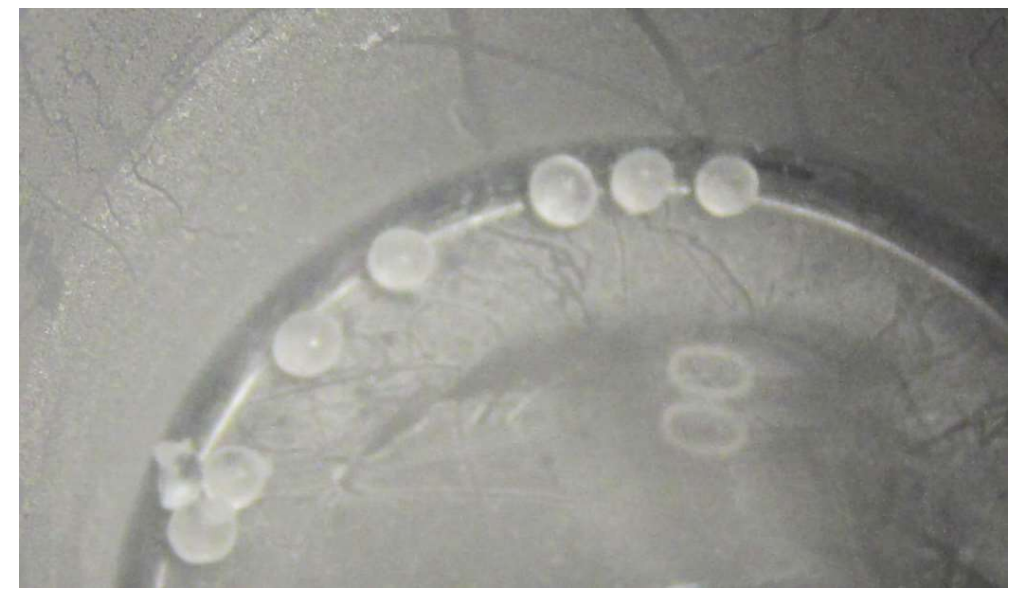

Figure 2. Ice Particles

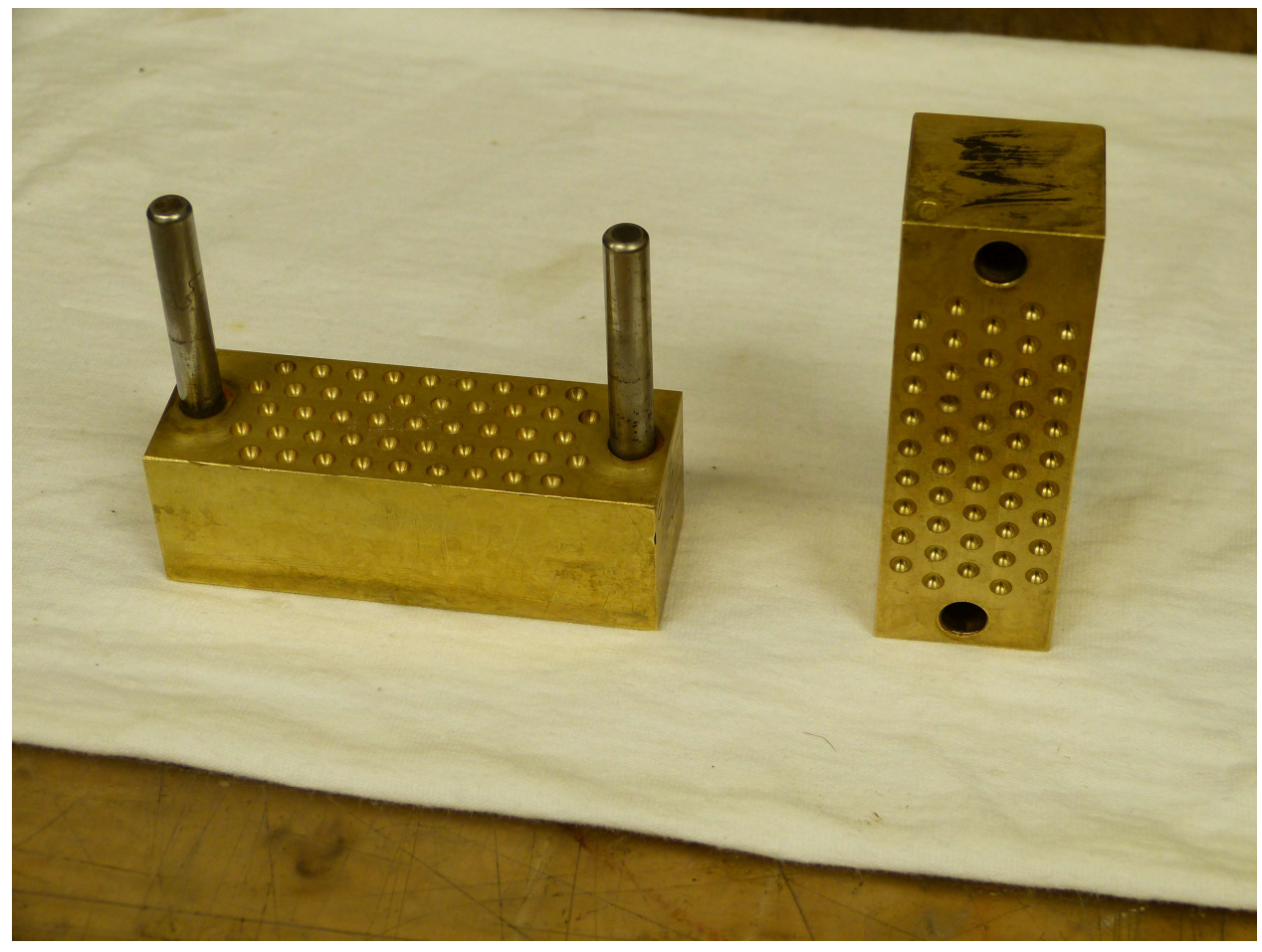

Figure 3. Metallic Mold for Generation of Ice Particles. Each half of the mold has a series of hemispherical hollow cavities that constitute a whole sphere when the two parts of the mold are brought together. An ice piece was compressed and crushed until the two halves of the mold touched each other. They were then separated, and spherical ice particles were removed for use in the experiment. 


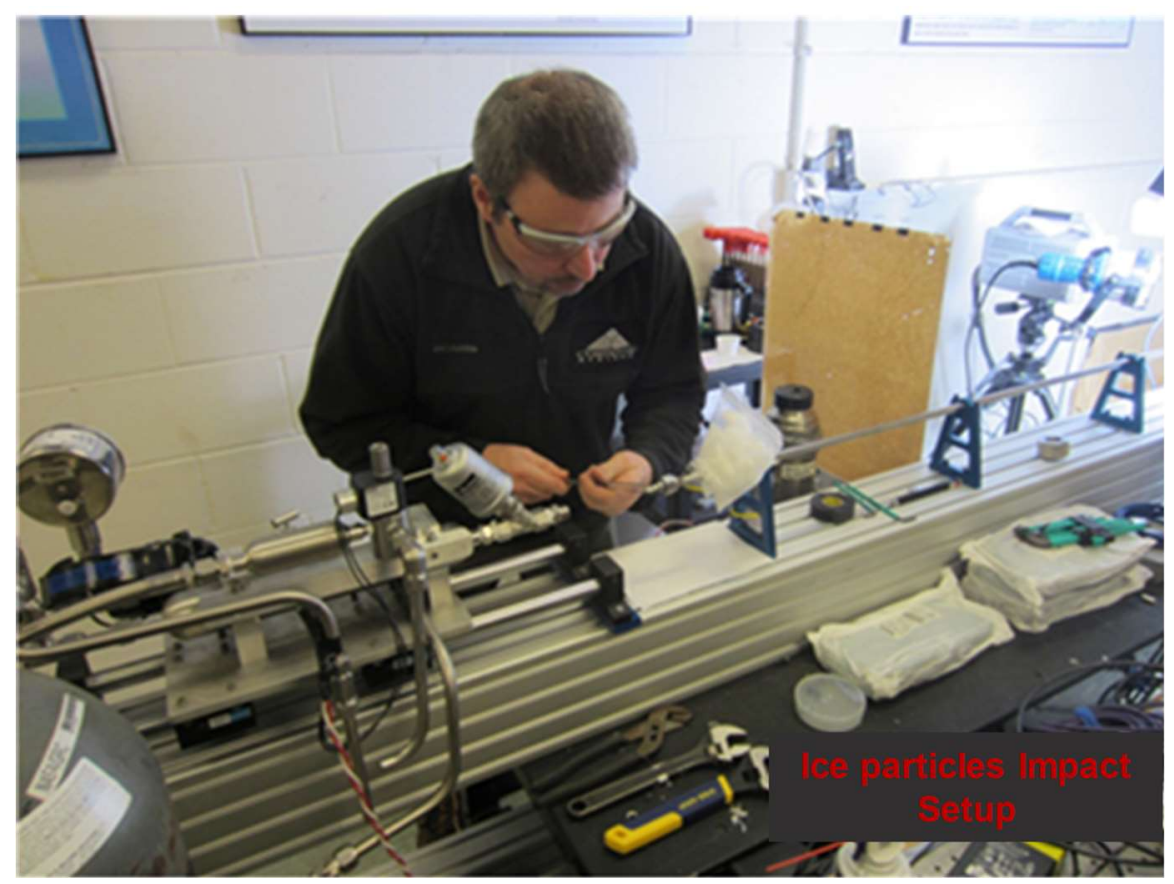

Figure 4. Pressure Gun Main Components. The pressure tank, the solenoid valve, the breech and the barrel are shown.

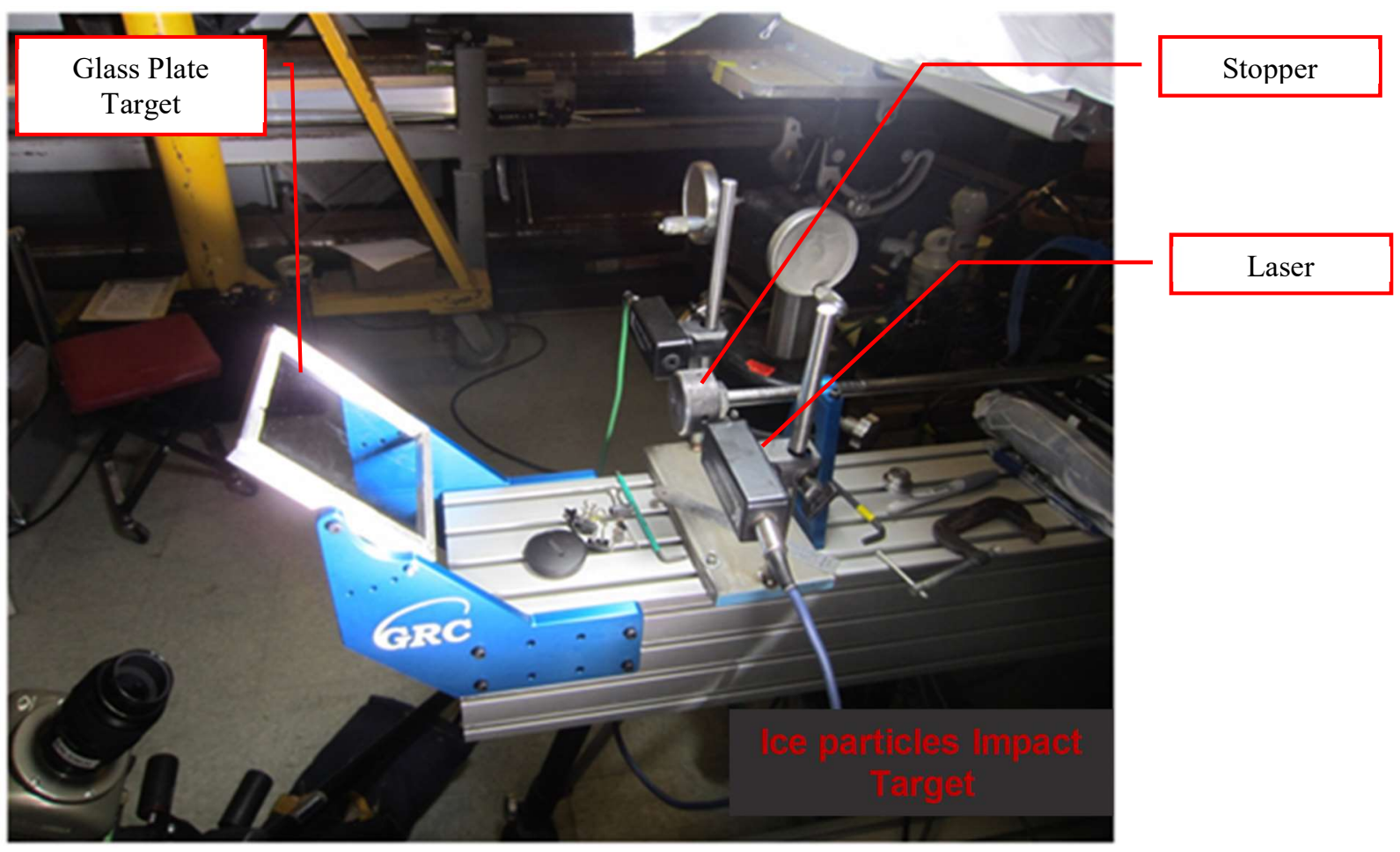

Figure 5. Stopper and Laser Triggering System. The glass plate target and the camera below the target also can be seen. 


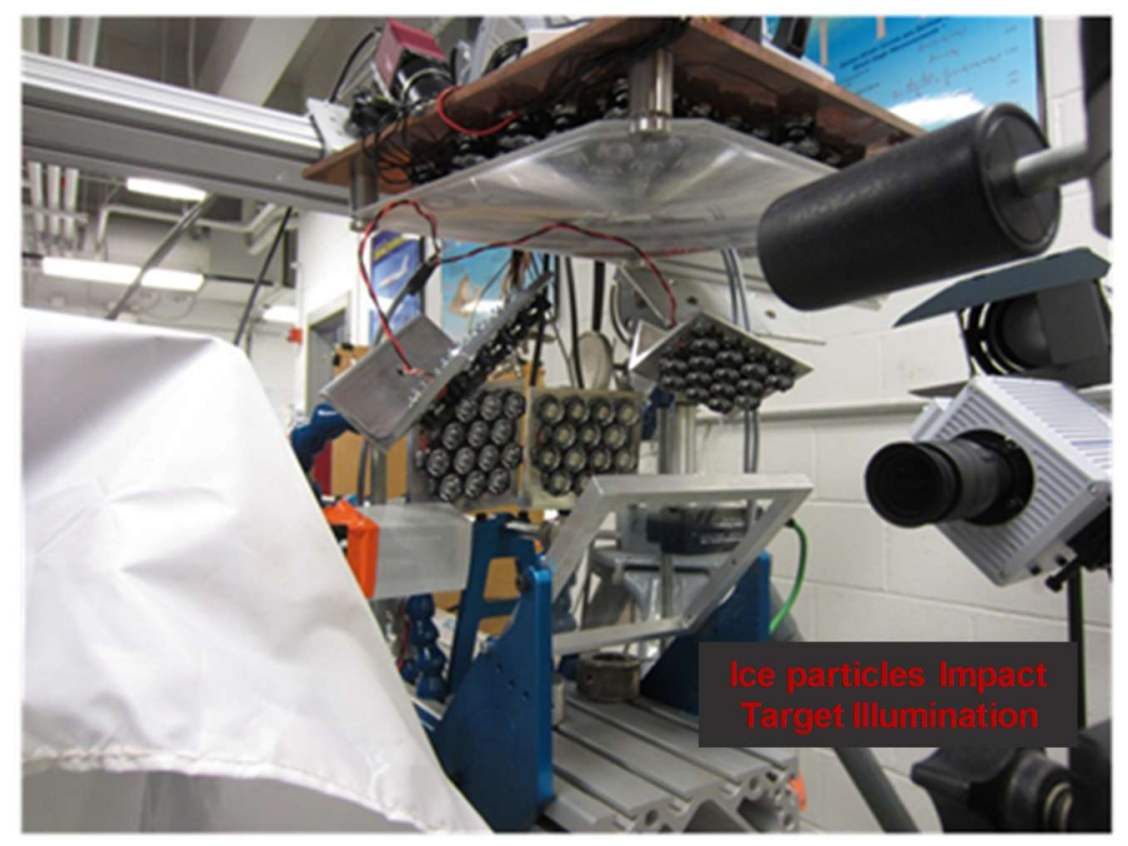

Figure 6. Illumination System used with the Single Frame Camera. The single frame camera can be seen in the upper middle part of the image. The side camera is on the right side of the image.

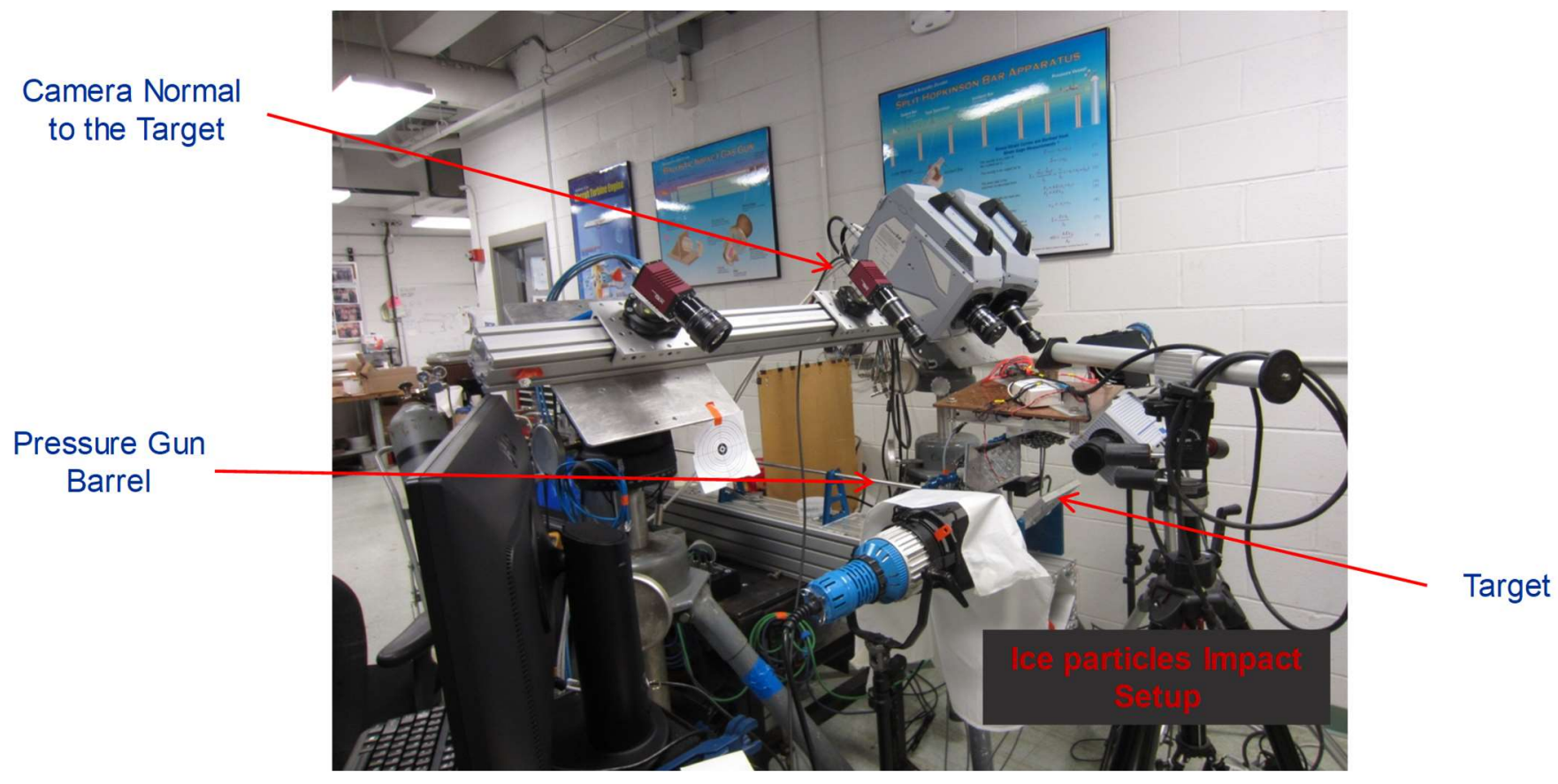

Figure 7. Camera Above and Normal to the Glass Plate Target. The camera was placed above the impact area on the target. The side camera and laser triggering were unchanged from the configuration in Figure 6. Illumination with banks of LEDs was coming from above the impact area. 


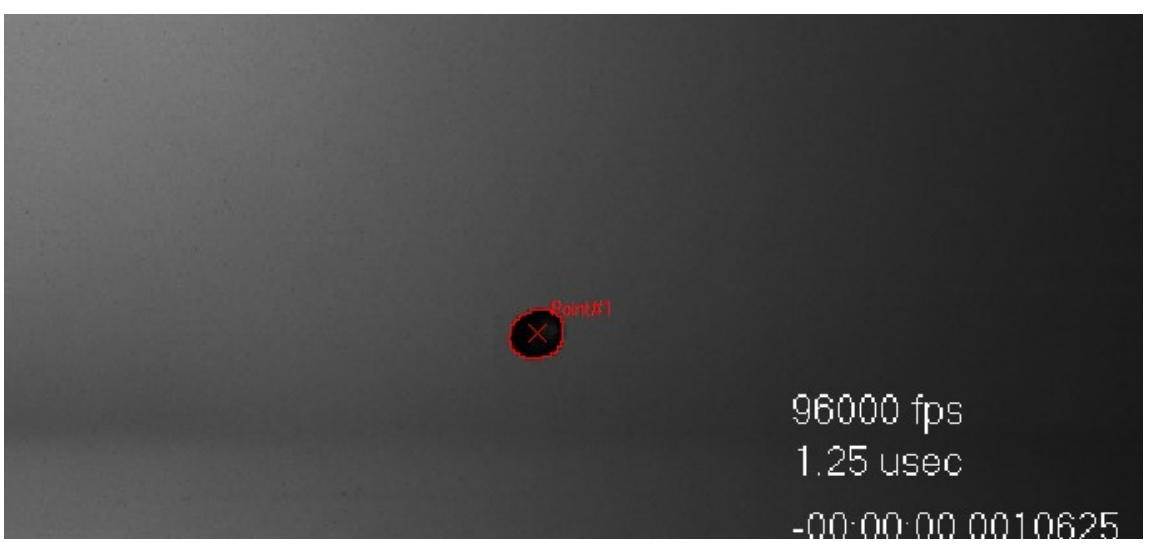

Figure 8. Example of particle tracking software. Software determines edges based on grey scale and calculated center of mass.

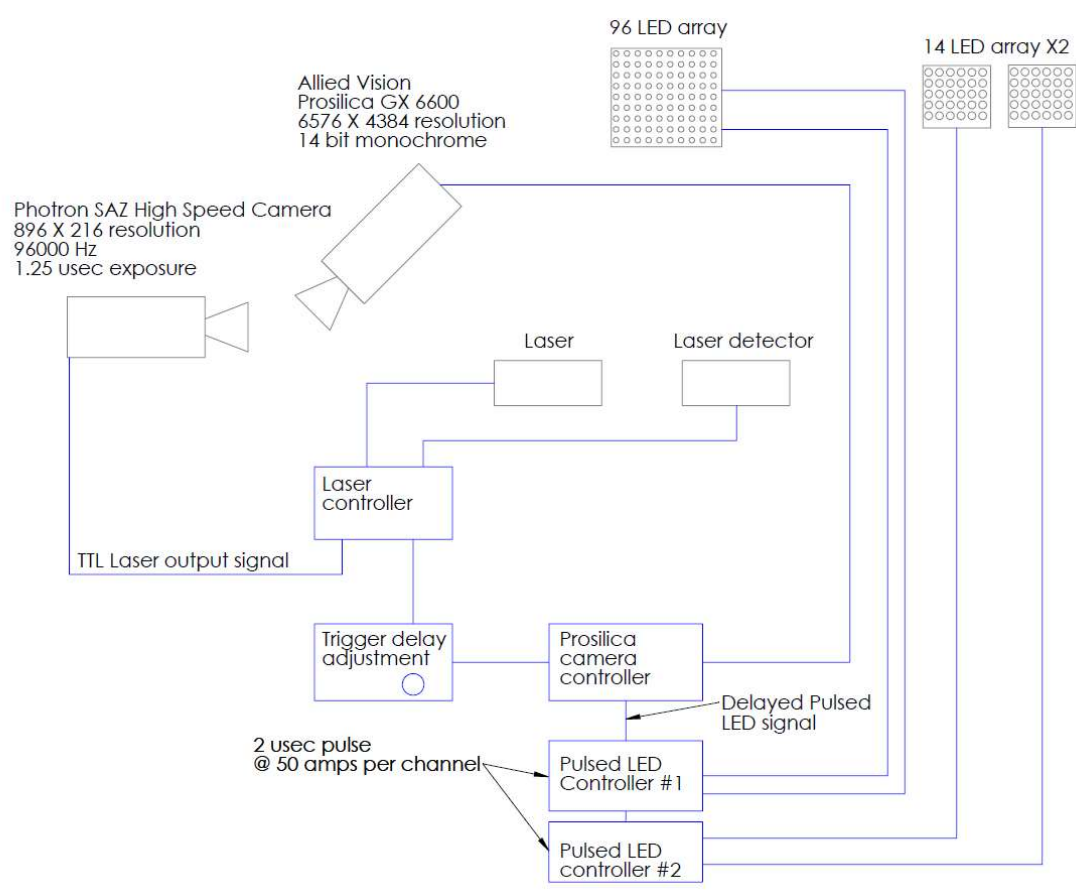

Figure 9. Schematic of pulsed LED and Prosilica camera system. 


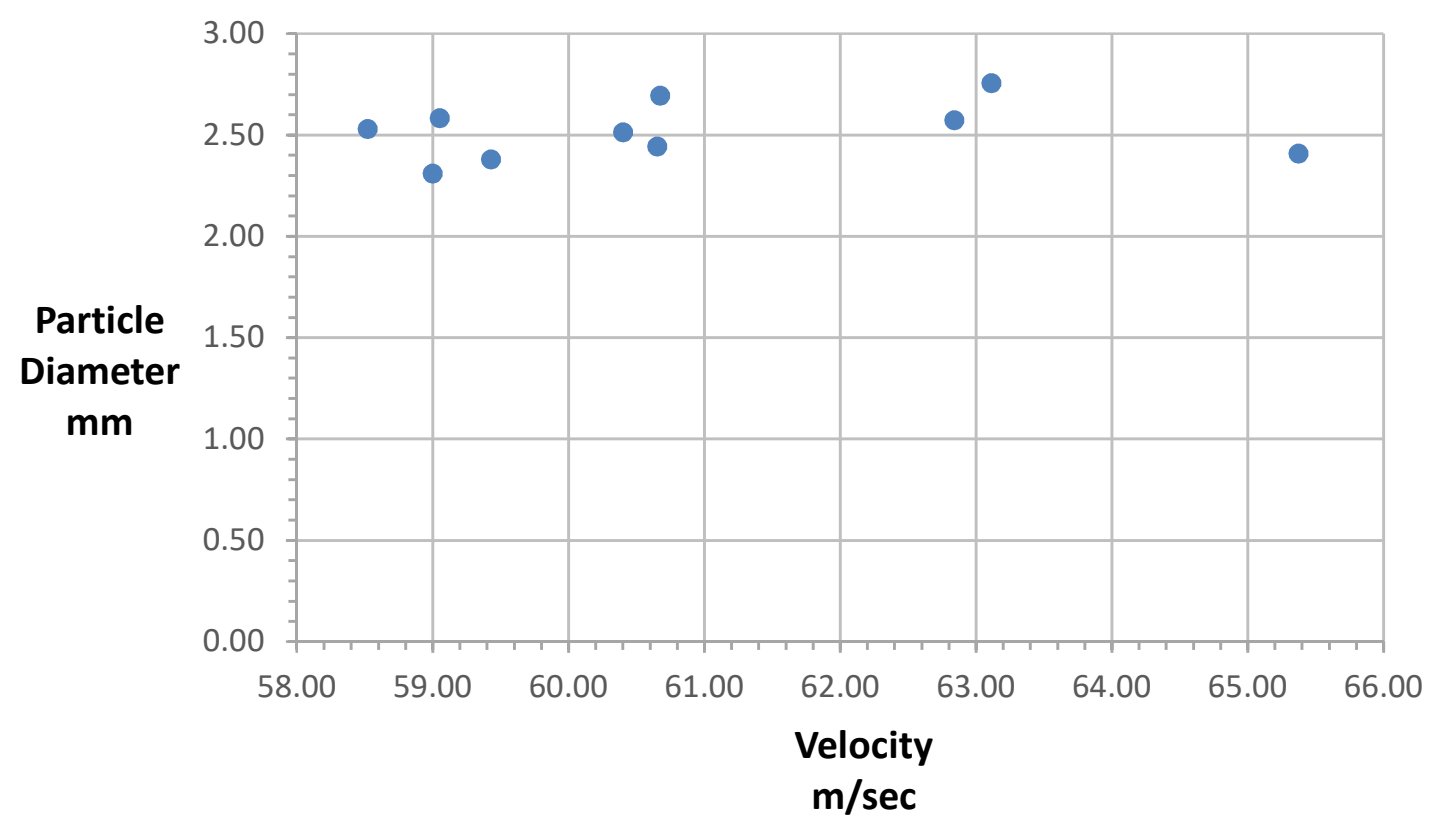

Figure 10. Particle Diameter against Velocity for 9 psi Test. The figure shows the velocity and diameter variability for 10 runs at a gun pressure of 9 psi.

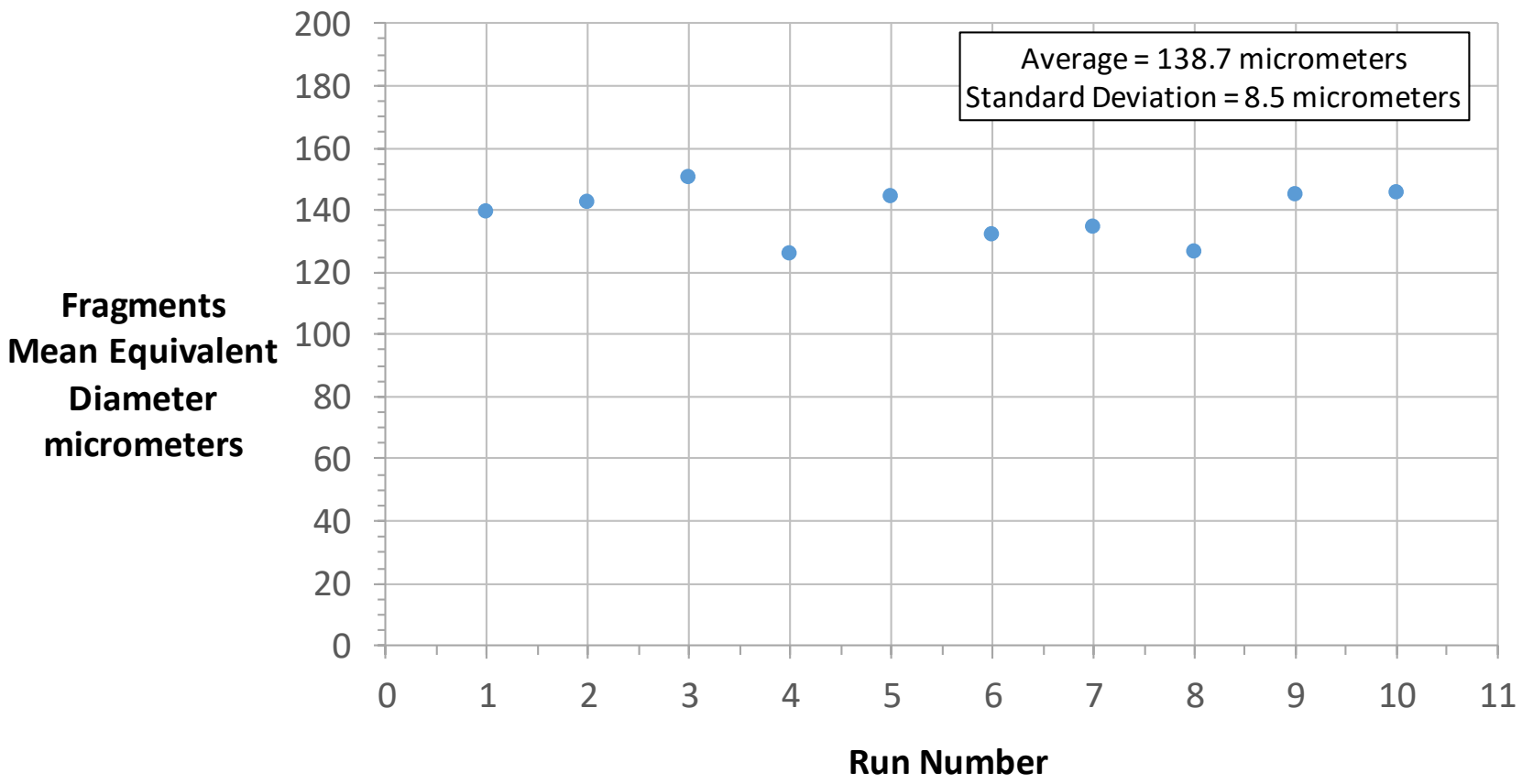

Figure 11. Mean Equivalent Diameter vs. Run Number for 9 psi Test. For each run, the mean equivalent diameter was calculated and plotted versus the run number. The average for all the runs was 138.7 micrometers. The standard deviation was 8.5 micrometers.

American Institute of Aeronautics and Astronautics 


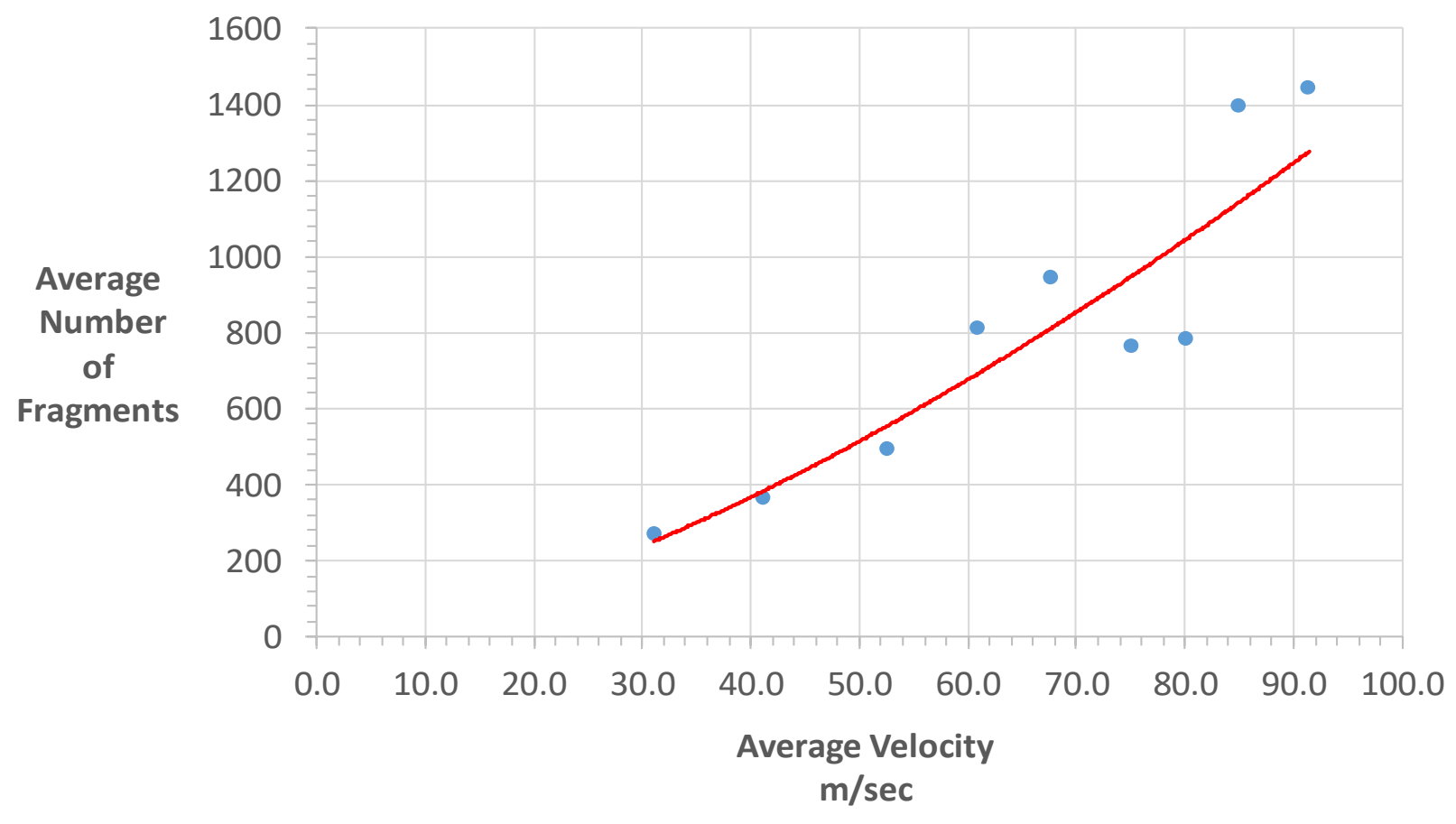

Figure 12. Number Fragments vs. Average Velocity for Tests 3psi through 20psi. For each gun pressure (test), the number of fragments and the velocities from the ten runs were averaged and plotted.

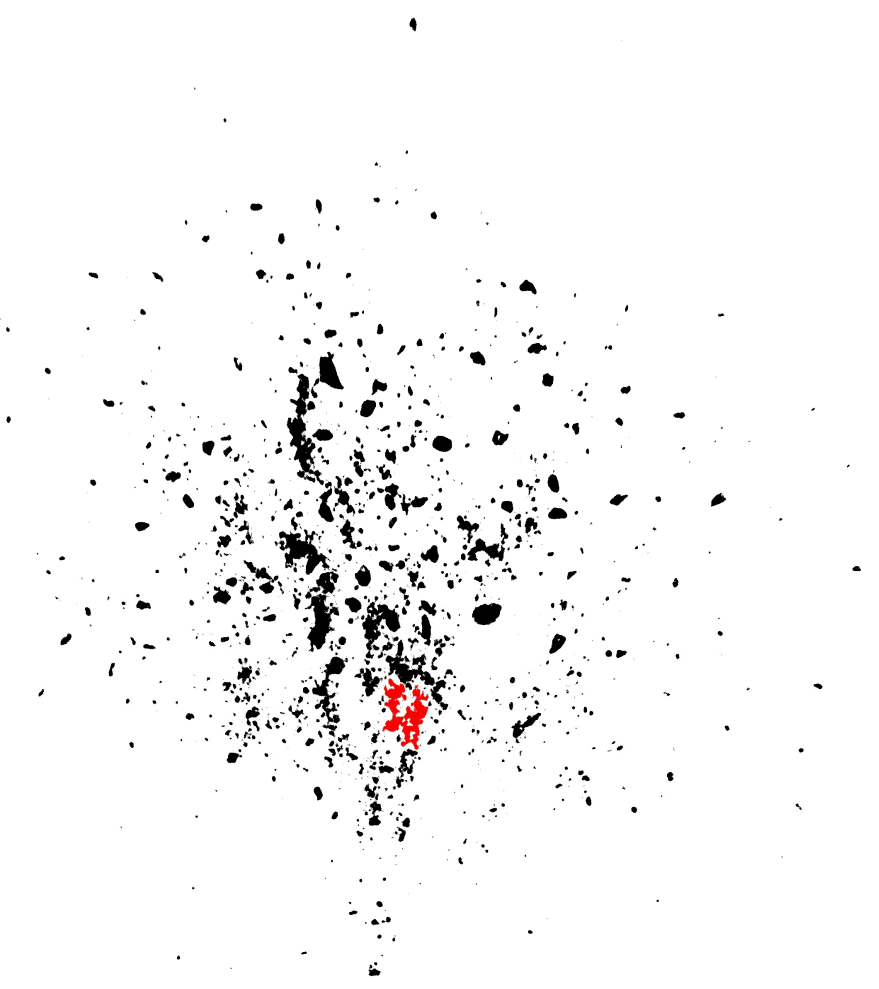

Figure 13. Fragments too close to each other analyzed as one large fragment, 20 psi Test. Example of a case where the data analysis program could not separate fragments too close to each other. The program segmented the fragments as one large one. An example is shown in red. Run 09-20 psi, diameter of impacting particle $2.6 \mathrm{~mm}$, velocity $92 \mathrm{~m} / \mathrm{sec}, 1430$ fragments

American Institute of Aeronautics and Astronautics 


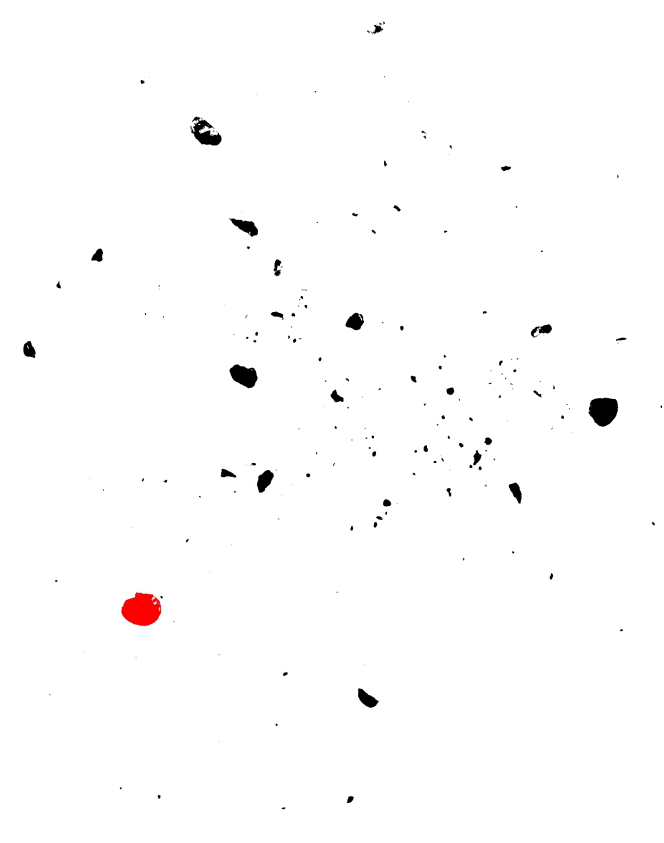

Figure 14. Segmented Image for Run 06, 3 psi. The largest fragment is shown in red. Impacting particle diameter $2.3 \mathrm{~mm}$, velocity $32 \mathrm{~m} / \mathrm{sec}$, number of fragments 226, mean equivalent diameter 149 micrometers. Histogram of this binary image is presented in Figure 15

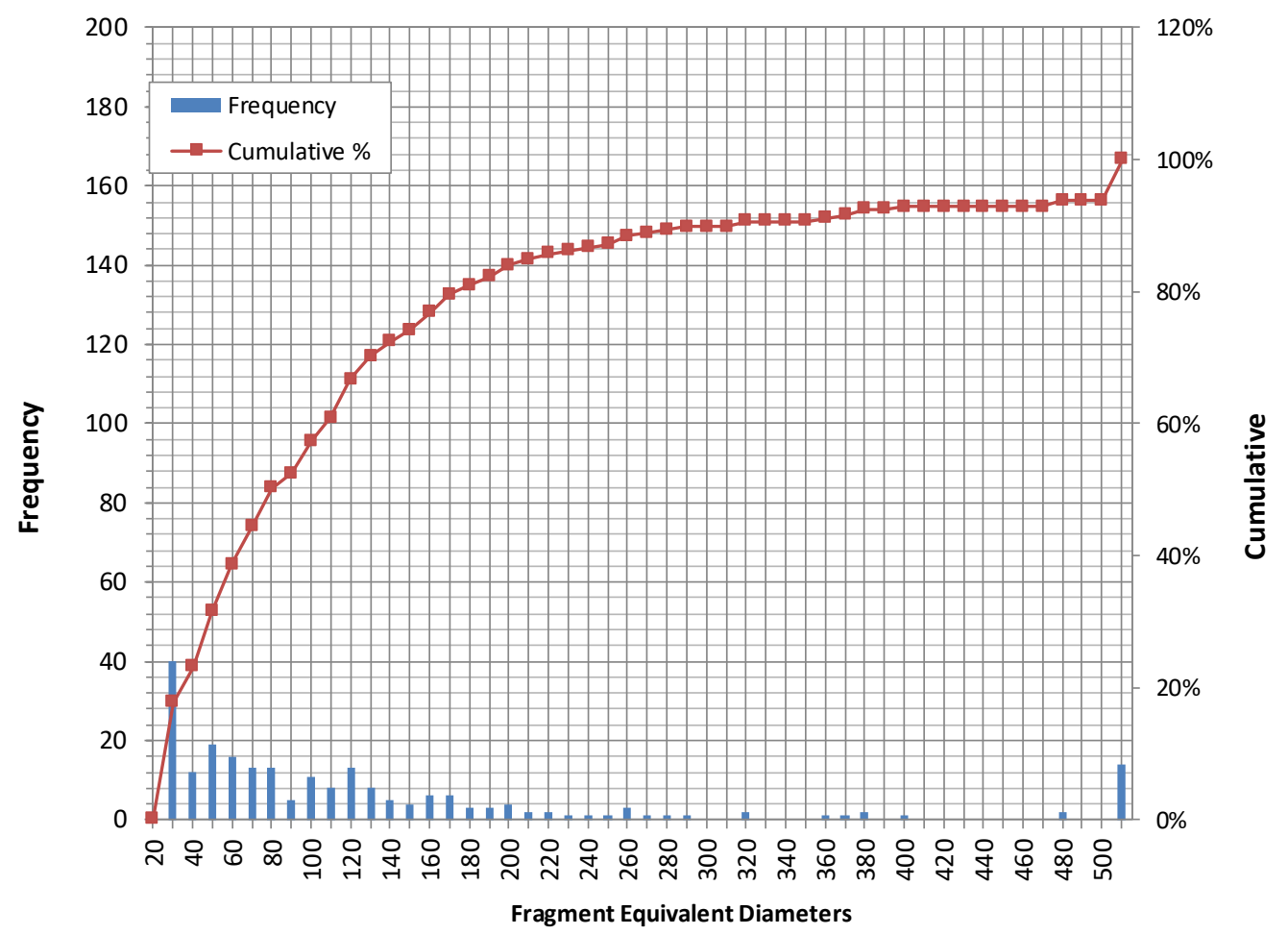

Figure 15. Fragments Equivalent Diameter Distribution - Histogram for Run 06, 3 psi. The histogram shows the number of fragments within a given equivalent diameter range for a bin size of 10 micrometers. Segmented image is shown in Figure 14 


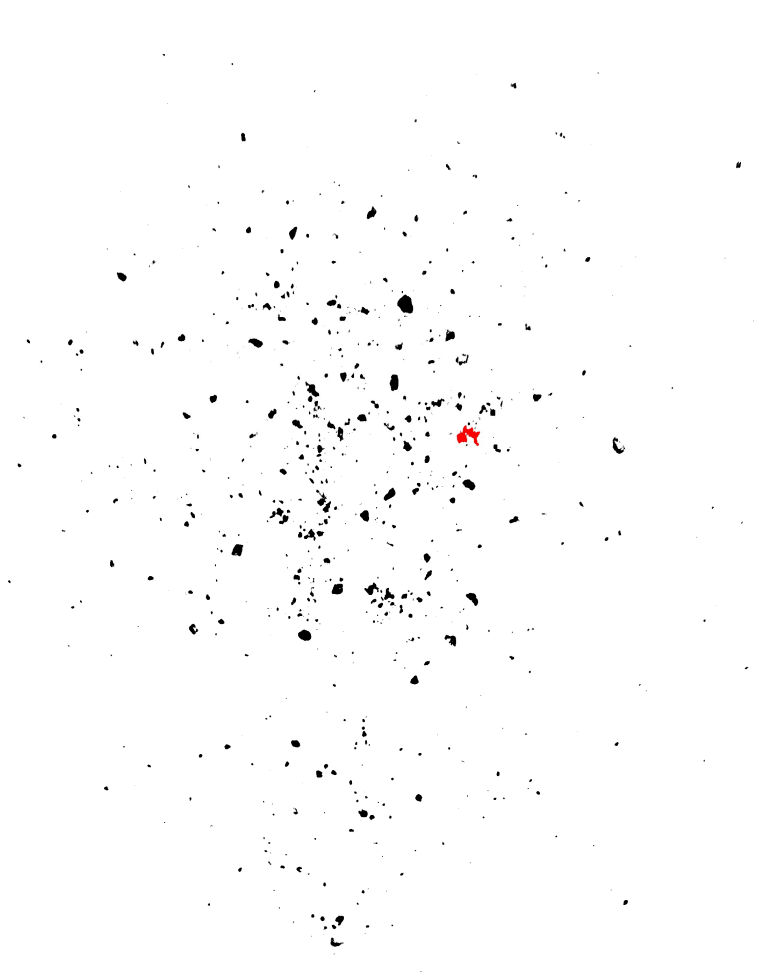

Figure 16. Segmented Image for Run 06, 20 psi. The largest fragment is shown in red. Impacting particle diameter $2.1 \mathrm{~mm}$, velocity $99 \mathrm{~m} / \mathrm{sec}$, number of fragments 863 , mean equivalent diameter 133 micrometers. Histogram of this binary image is presented in Figure 17

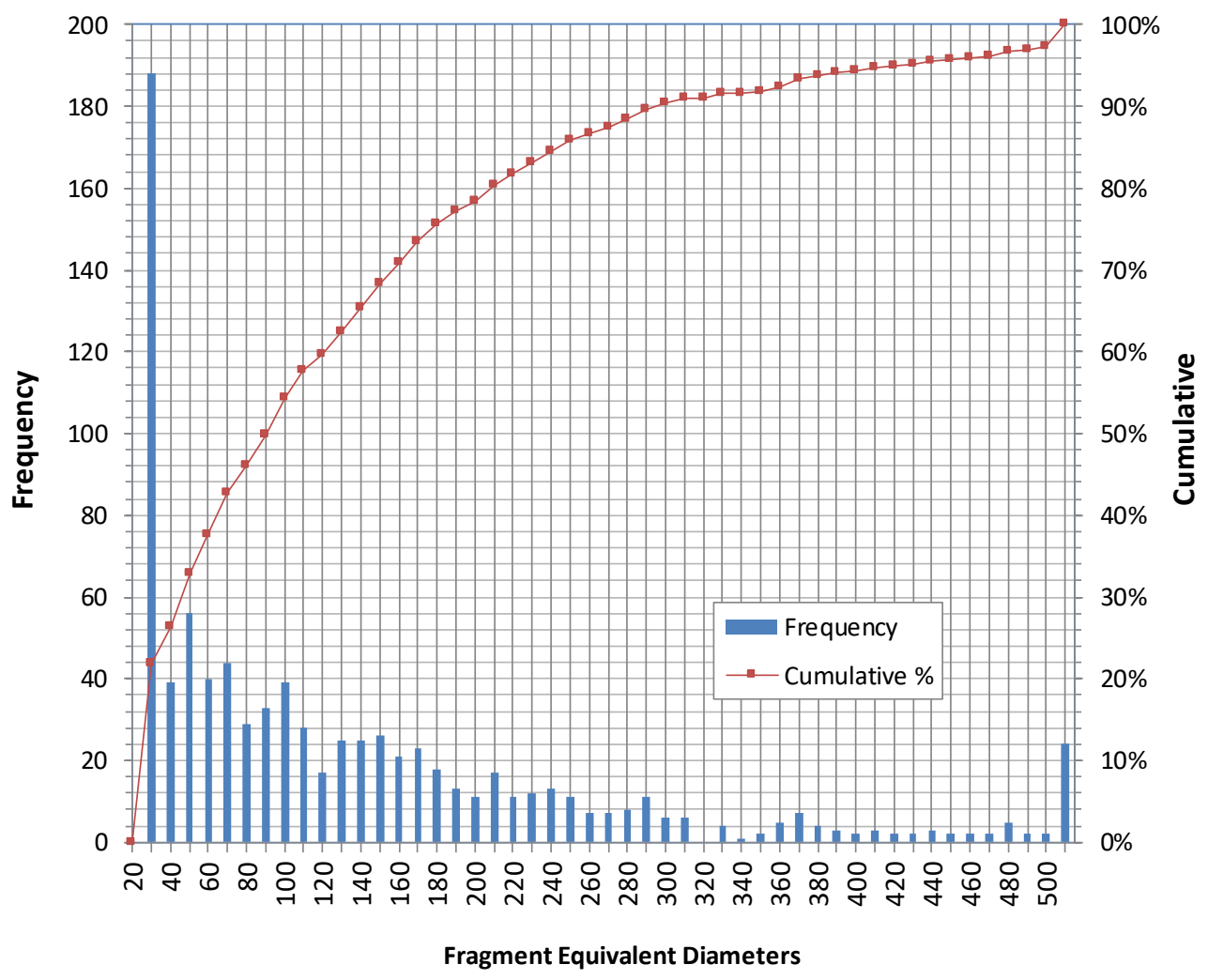

Figure 17. Fragments Equivalent Diameter Distribution - Histogram for Run 06, 20 psi. The histogram shows the number of fragments within a given equivalent diameter range for a bin size of 10 micrometers. Segmented image is shown in Figure 16. 

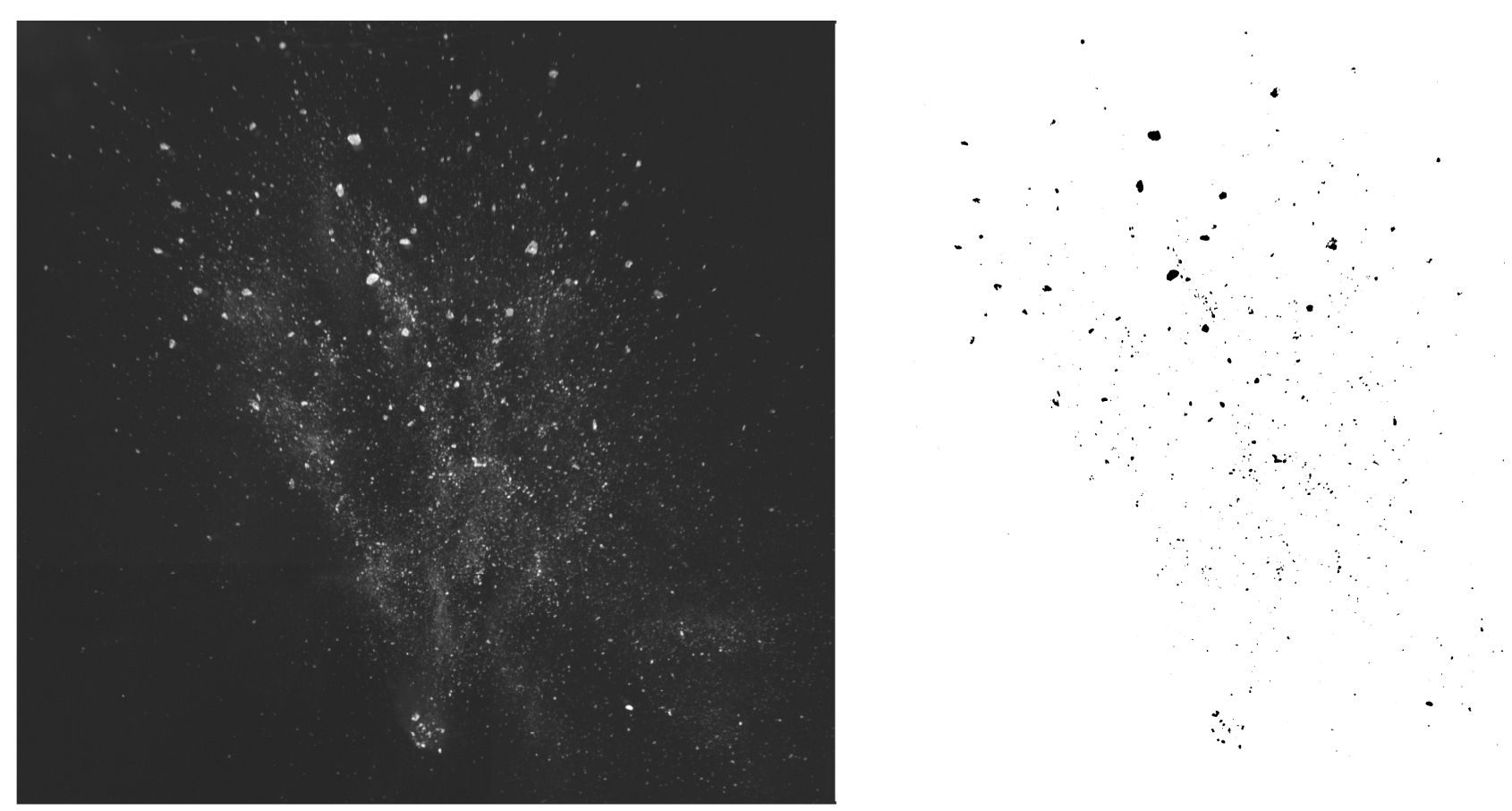

Figure 18. Comparison between Original Image and Thresholded Image. The original image and the segmented binary image are shown side-by-side. The original image is from the impact of a particle with diameter $2.3 \mathrm{~mm}$, impact velocity $97 \mathrm{~m} / \mathrm{sec}$, target angle $45^{\circ}$, resolution 48.46 pixels/millimeter, smallest fragment size that could be measured 20.6 micrometers.

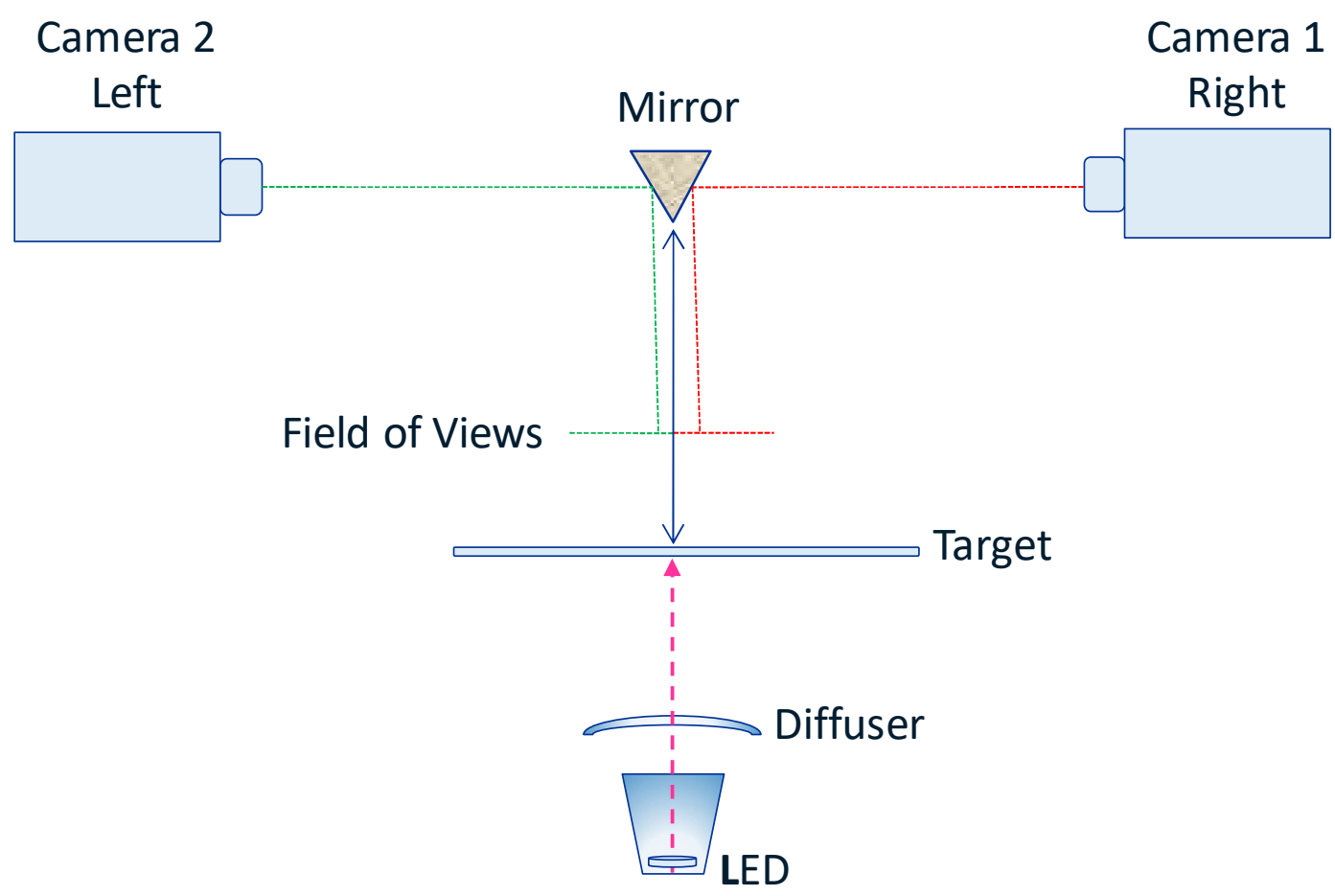

Figure 19. Schematic of Modified Setup to improve Resolution. Two Prosilica GX6600 cameras are pointed towards the triangular mirror. Each camera covers half the field of view. Field of view for each camera: $56 \mathrm{~mm}$ horizontal $\mathrm{x} 37 \mathrm{~mm}$ vertical. Resolutions between 5-10 micrometers per pixel were reached. 


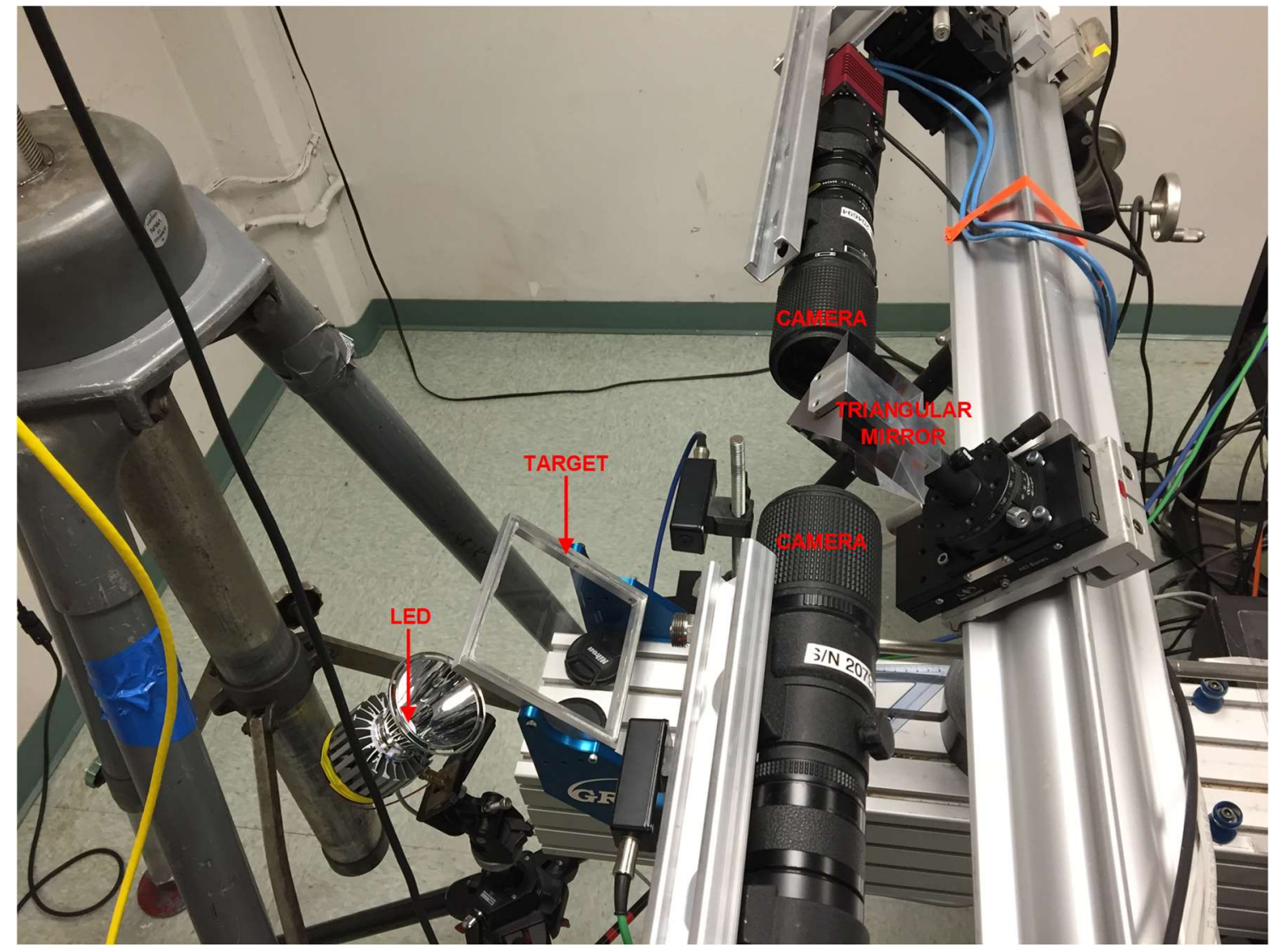

Figure 20. Modified Setup to improve Resolution. Two Prosilica GX6600 cameras are pointing toward the triangular mirror. The target and the LED illumination are shown. The diffuser screen is not shown.

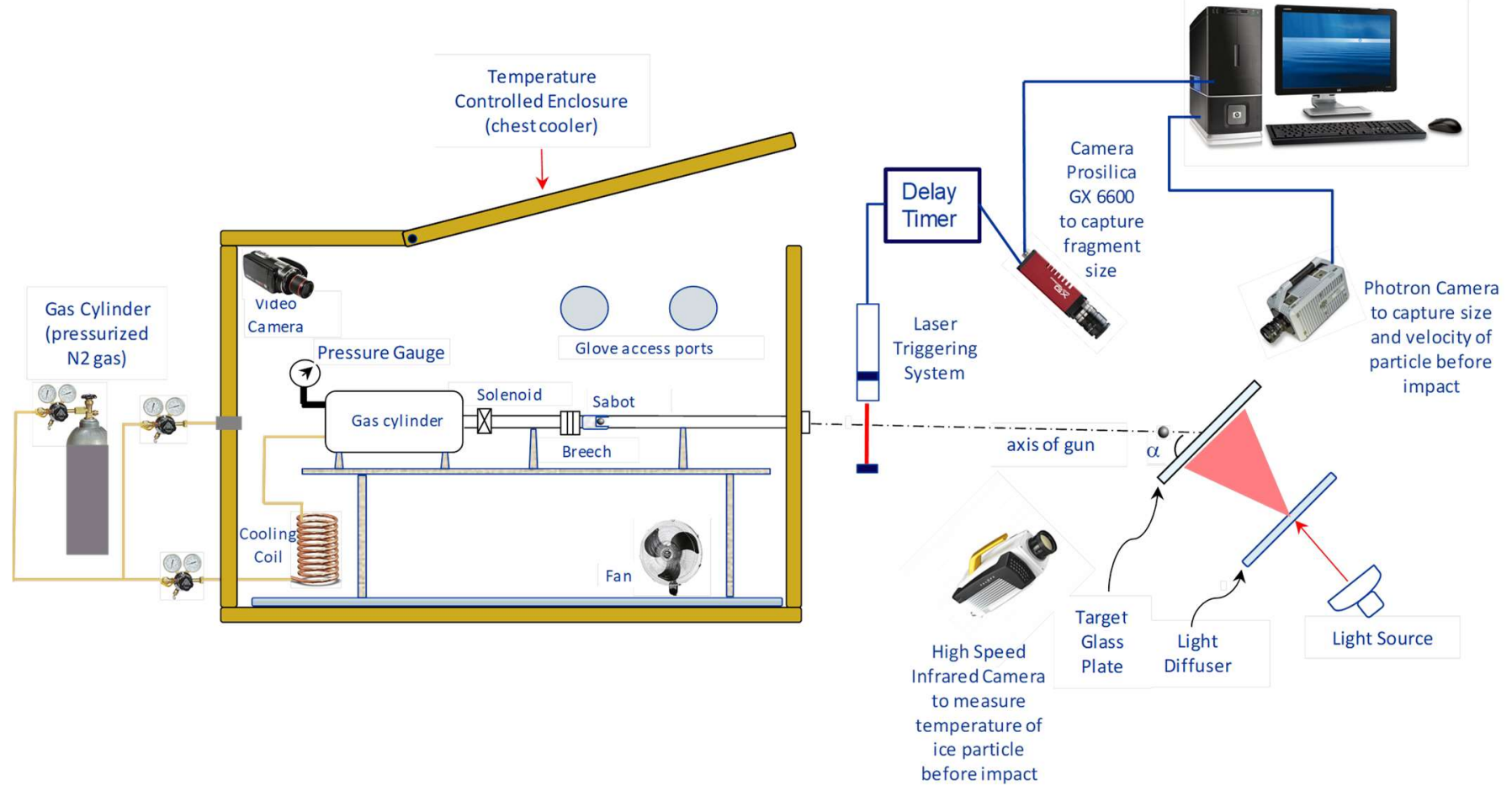

Figure 21. Conceptual View of Setup for next round of Experiments. The new experimental setup is based on lessons learned from past experiments at the Ballistics Impact Laboratory. The new setup is intended for particle sizes from 200 to 2000 micrometers and a range of testing conditions. 